\title{
Lipid profiling in epicardial and subcutaneous adipose tissue of patients with coronary artery disease
}

\section{Supplementary materials}

Petra Tomášováa,b, Martina Čermákováa, Helena Pelantováa , Marek Veckab ${ }^{b}$ Helena Kratochvílovád,g, Michal Lipše, Jaroslav Lindnerf, Peter Ivákh, Ivan Netukah, Blanka Šediváa,c, Martin Haluzík ${ }^{\mathrm{d}, \mathrm{i}}$, Marek

Kuzma ${ }^{a, *}$

a Institute of Microbiology, Czech Academy of Sciences, Vídeňská 1083, 14220 Prague 4, Czech Republic

b 4th Medical Department, First Faculty of Medicine, Charles University and General Faculty Hospital in Prague,

U Nemocnice 2, 12808 Praha 2, Czech Republic

' Faculty of Applied Sciences, University of West Bohemia, Univerzitní 8, 30614 Plzeň, Czech Republic

${ }^{d}$ Institute of Medical Biochemistry and Laboratory Diagnostics; First Faculty of Medicine, Charles University and General University Hospital in Prague, U Nemocnice 2, 128 08, Prague 2, Czech Republic

e Department of Anaesthesiology, Resuscitation and Intensive Care, First Faculty of Medicine, Charles University and General University Hospital in Prague, U Nemocnice 2, 128 08, Prague 2, Czech Republic

${ }^{f}$ 2nd Department of Surgery - Department of Cardiovascular Surgery, First Faculty of Medicine, Charles

University and General University Hospital in Prague, U Nemocnice 2, 128 08, Prague 2, Czech Republic

${ }^{\mathrm{g}}$ Centre for Experimental Medicine, ${ }^{\mathrm{h} D e p a r t m e n t}$ of Cardiovascular Surgery and

'Diabetes Centre, Institute for Clinical and Experimental Medicine, Vídeňská 1958/9, 140 21, Prague 4, Czech

Republic

* Corresponding author: Marek Kuzma, kuzma@biomed.cas.cz

\begin{tabular}{|c|c|c|}
\hline Item & Title & page \\
\hline Fig. S1 & $\begin{array}{l}\text { MS/MS spectrum of MAG(16:0) in adipose tissue obtained using positive ionization } \\
\text { mode }\end{array}$ & S-3 \\
\hline Fig. S2 & $\begin{array}{l}\text { MS/MS spectrum of DAG(18:1/16:0) in adipose tissue obtained using positive } \\
\text { ionization mode }\end{array}$ & S-3 \\
\hline Fig. S3 & $\begin{array}{l}\text { MS/MS spectrum of DAG(18:2/18:2) in adipose tissue obtained using positive } \\
\text { ionization mode }\end{array}$ & S-4 \\
\hline Fig. S4 & $\begin{array}{l}\text { MS/MS spectrum of TAG(16:0/18:1/15:0) in adipose tissue obtained using positive } \\
\text { ionization mode }\end{array}$ & S-4 \\
\hline Fig. S5 & $\begin{array}{l}\text { MS/MS spectrum of TAG(18:1/17:0/16:0) in adipose tissue obtained using positive } \\
\text { ionization mode }\end{array}$ & S-5 \\
\hline Fig. S6 & $\begin{array}{l}\text { MS/MS spectrum of TAG(18:1/16:1/12:0) in adipose tissue obtained using positive } \\
\text { ionization mode }\end{array}$ & S-5 \\
\hline Fig. S7 & $\begin{array}{l}\text { MS/MS spectrum of TAG(18:1/16:0/12:0) in adipose tissue obtained using positive } \\
\text { ionization mode }\end{array}$ & S-6 \\
\hline Fig. S8 & $\begin{array}{l}\text { MS/MS spectrum of TAG(18:1/16:0/14:0) in adipose tissue obtained using positive } \\
\text { ionization mode }\end{array}$ & S-6 \\
\hline Fig. S9 & $\begin{array}{l}\text { MS/MS spectrum of TAG(18:1/18:1/17:1) in adipose tissue obtained using positive } \\
\text { ionization mode }\end{array}$ & S-7 \\
\hline Fig. S10 & $\begin{array}{l}\text { MS/MS spectrum of TAG(18:1/18:2/20:1) in adipose tissue obtained using positive } \\
\text { ionization mode }\end{array}$ & S-7 \\
\hline Fig. S11 & $\begin{array}{l}\text { MS/MS spectrum of TAG(16:0/14:0/14:0) in adipose tissue obtained using positive } \\
\text { ionization mode }\end{array}$ & $S-8$ \\
\hline
\end{tabular}




\begin{tabular}{|c|c|c|}
\hline Fig. S12 & $\begin{array}{l}\text { MS/MS spectrum of TAG(16:1/18:1/15:0) in adipose tissue obtained using positive } \\
\text { ionization mode }\end{array}$ & $\mathrm{S}-8$ \\
\hline Fig. S13 & $\begin{array}{l}\text { MS/MS spectrum of TAG(16:0/12:0/12:0) in adipose tissue obtained using positive } \\
\text { ionization mode }\end{array}$ & S-9 \\
\hline Fig. S14 & $\begin{array}{l}\text { MS/MS spectrum of TAG(16:1/16:0/15:1) in adipose tissue obtained using positive } \\
\text { ionization mode }\end{array}$ & S-9 \\
\hline Fig. S15 & $\begin{array}{l}\text { MS/MS spectrum of dihydroxycholesterol in adipose tissue obtained using positive } \\
\text { ionization mode }\end{array}$ & S-10 \\
\hline Fig. S16 & $\begin{array}{l}\text { MS/MS spectrum of PS(18:0/18:1) in adipose tissue obtained using negative } \\
\text { ionization mode }\end{array}$ & S-10 \\
\hline Fig. S17 & $\begin{array}{l}\text { MS/MS spectrum of LysoPE(18:1) in adipose tissue obtained using negative } \\
\text { ionization mode }\end{array}$ & S-11 \\
\hline Fig. S18 & $\begin{array}{l}\text { MS/MS spectrum of LysoPE(18:2) in adipose tissue obtained using negative } \\
\text { ionization mode }\end{array}$ & S-11 \\
\hline Fig. S19 & $\begin{array}{l}\text { MS/MS spectrum of LysoPE(20:4) in adipose tissue obtained using negative } \\
\text { ionization mode }\end{array}$ & S-12 \\
\hline Fig. S20 & $\begin{array}{l}\text { MS/MS spectrum of LysoPC(16:0) in adipose tissue obtained using positive ionization } \\
\text { mode }\end{array}$ & S-12 \\
\hline Fig. S21 & $\begin{array}{l}\text { MS/MS spectrum of LysoPC(18:1) in adipose tissue obtained using positive ionization } \\
\text { mode }\end{array}$ & S-13 \\
\hline Fig. S22 & $\begin{array}{l}\text { MS/MS spectrum of LysoPC(18:2) in adipose tissue obtained using positive ionization } \\
\text { mode }\end{array}$ & S-13 \\
\hline Fig. S23 & $\begin{array}{l}\text { MS/MS spectrum of } \mathrm{PC}(32: 0) \text { in adipose tissue obtained using positive ionization } \\
\text { mode }\end{array}$ & S-14 \\
\hline Fig. S24 & $\begin{array}{l}\text { MS/MS spectrum of } \mathrm{PC}(32: 1) \text { in adipose tissue obtained using positive ionization } \\
\text { mode }\end{array}$ & S-14 \\
\hline Fig. S25 & $\begin{array}{l}\text { MS/MS spectrum of } \mathrm{PC}(34: 0) \text { in adipose tissue obtained using positive ionization } \\
\text { mode }\end{array}$ & S-15 \\
\hline Fig. S26 & $\begin{array}{l}\text { MS/MS spectrum of Cer(d18:1/22:0) in adipose tissue obtained using positive } \\
\text { ionization mode }\end{array}$ & S-15 \\
\hline Fig. S27 & $\begin{array}{l}\text { MS/MS spectrum of SM(36:1) in adipose tissue obtained using positive ionization } \\
\text { mode }\end{array}$ & S-16 \\
\hline Fig. S28 & $\begin{array}{l}\text { MS/MS spectrum of SM(40:1) in adipose tissue obtained using positive ionization } \\
\text { mode }\end{array}$ & S-16 \\
\hline Fig. S29 & $\begin{array}{l}\text { MS/MS spectrum of SM(42:2) in adipose tissue obtained using positive ionization } \\
\text { mode }\end{array}$ & S-17 \\
\hline Fig. S30 & PLS-DA scores plot for SAT & S-18 \\
\hline Fig. S31 & PLS-DA scores plot for EAT & S-19 \\
\hline Fig. S32 & Boxplots of significantly changed lipids & S-20-24 \\
\hline Fig. S33 & Correlation of significantly changed lipid in EAT and biochemical parameters & S-25-27 \\
\hline Fig. S34 & Correlation of significantly changed lipid in SAT and biochemical parameters & S-28 \\
\hline
\end{tabular}




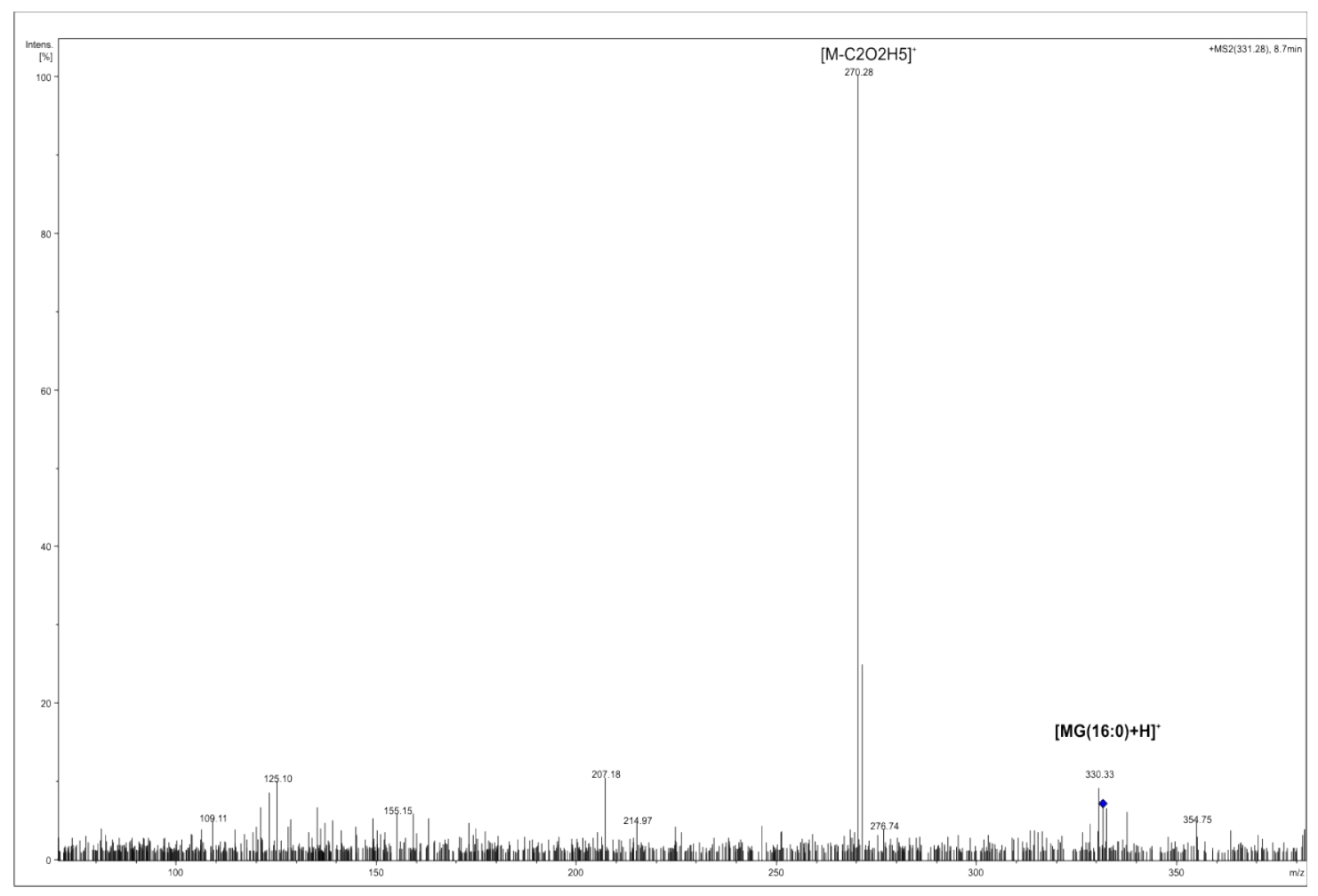

Fig. S1: MS/MS spectrum of MAG(16:0) in adipose tissue obtained using positive ionization mode

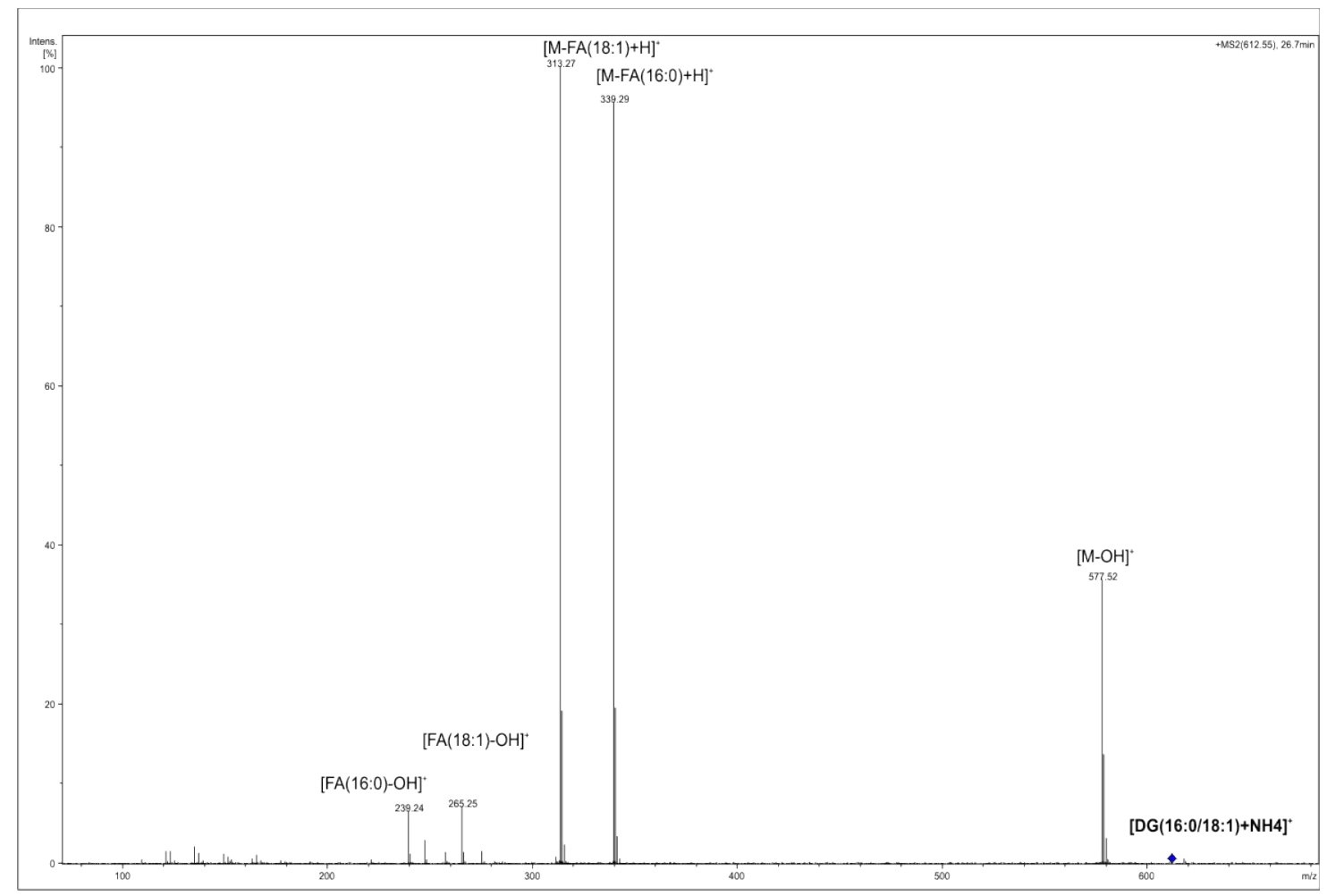

Fig. S2: MS/MS spectrum of DAG(18:1/16:0) in adipose tissue obtained using positive ionization mode 


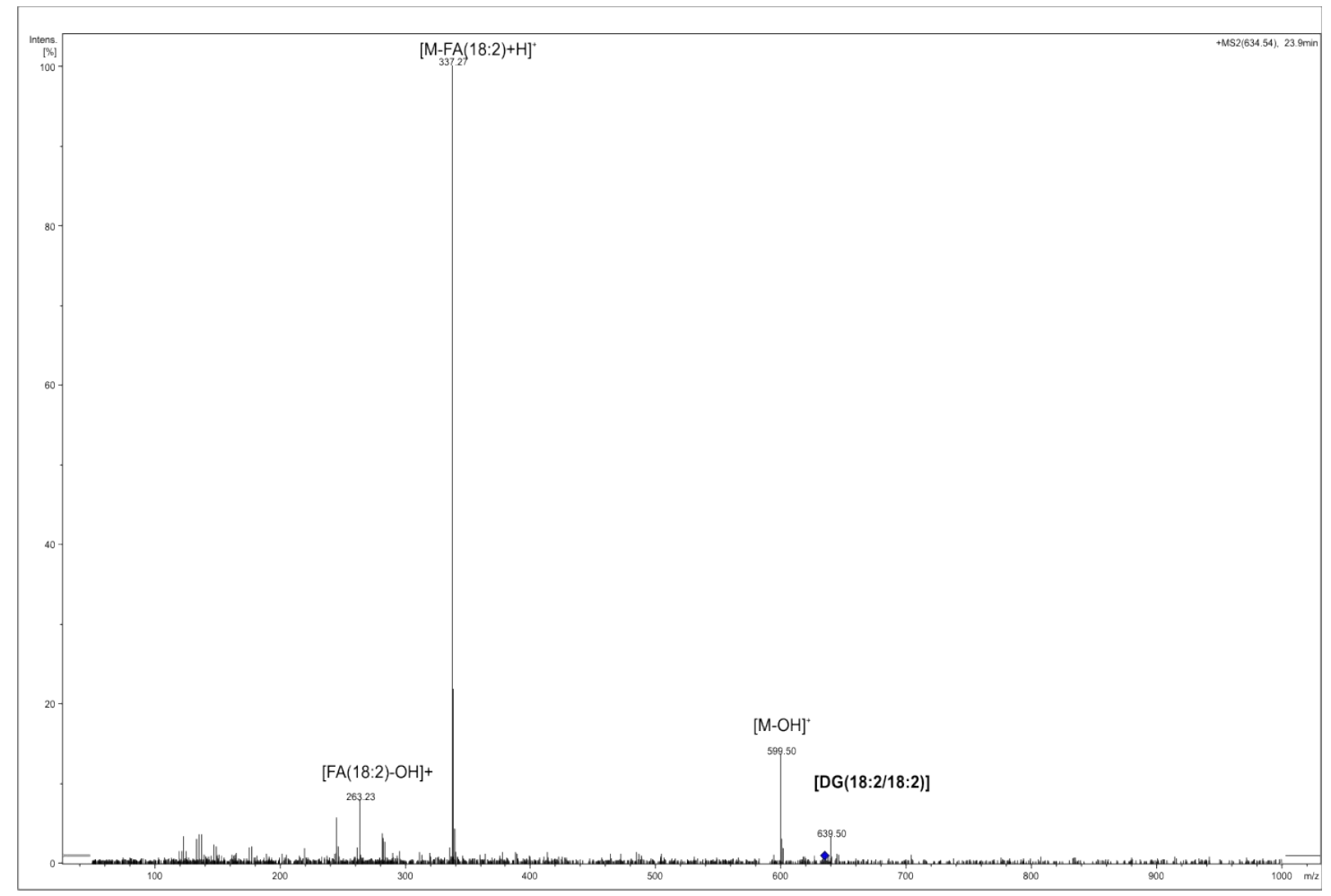

Fig. S3: MS/MS spectrum of DAG(18:2/18:2) in adipose tissue obtained using positive ionization mode

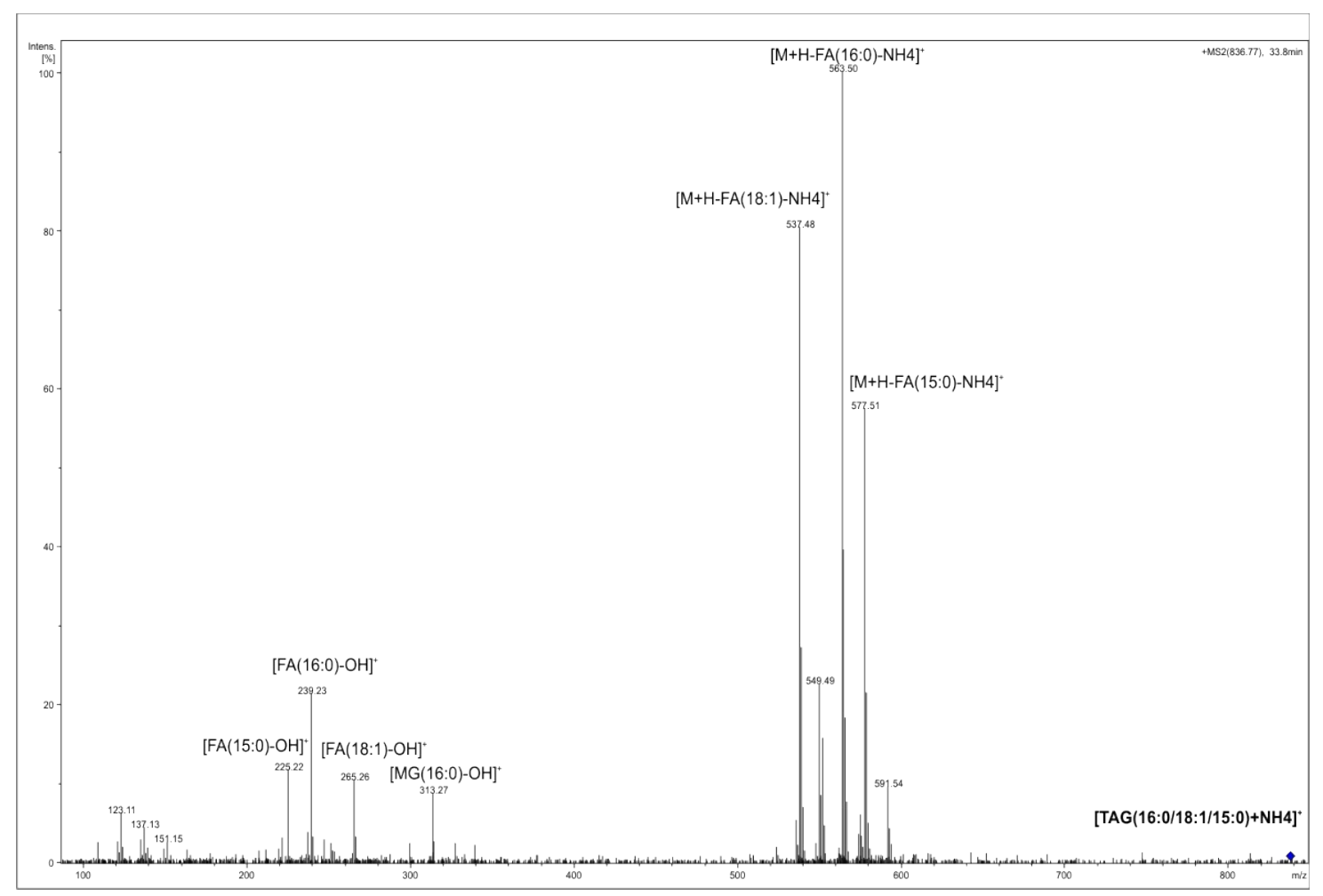

Fig. S4: MS/MS spectrum of TAG(16:0/18:1/15:0) in adipose tissue obtained using positive ionization mode 


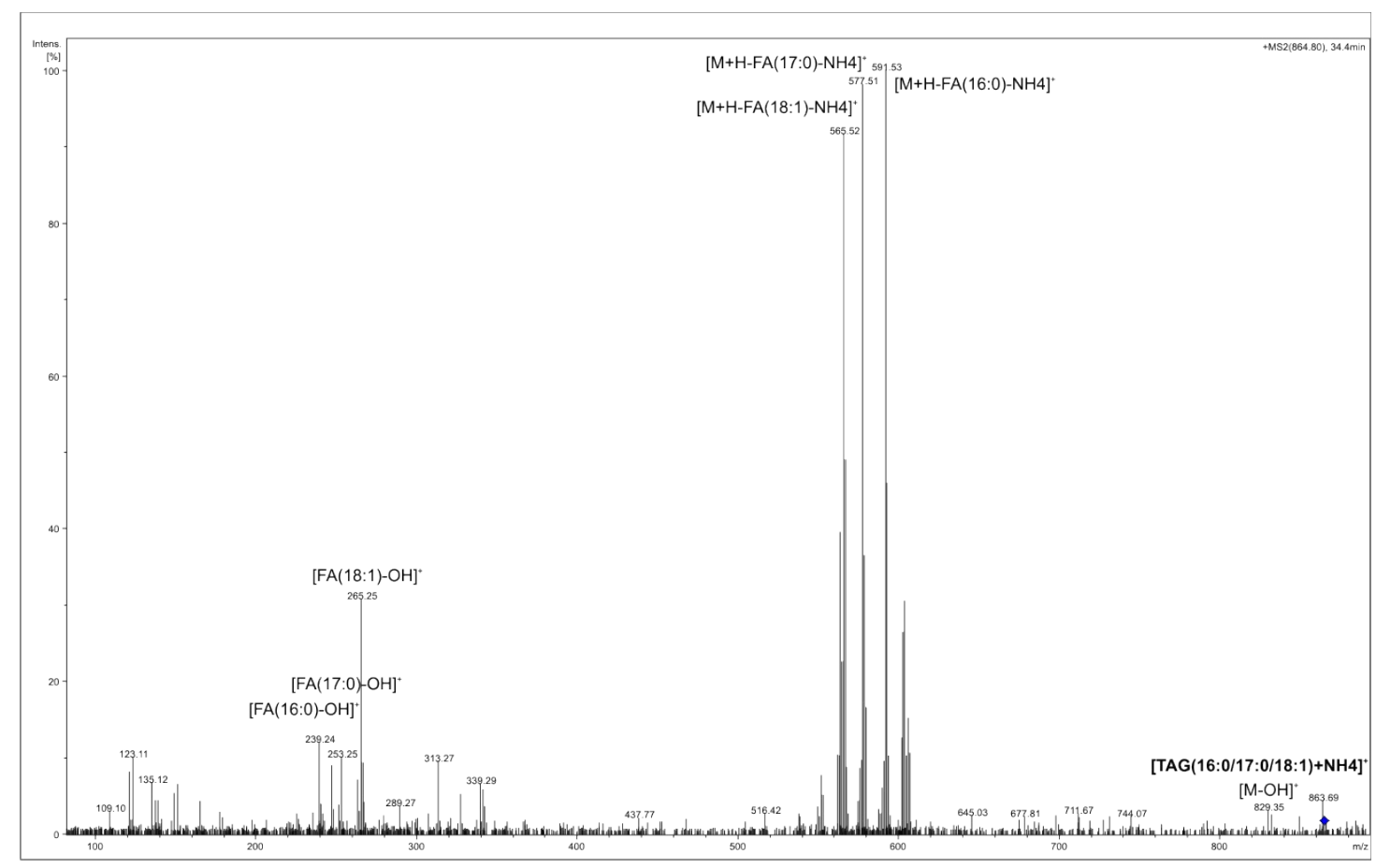

Fig. S5: MS/MS spectrum of TAG(18:1/17:0/16:0) in adipose tissue obtained using positive ionization mode

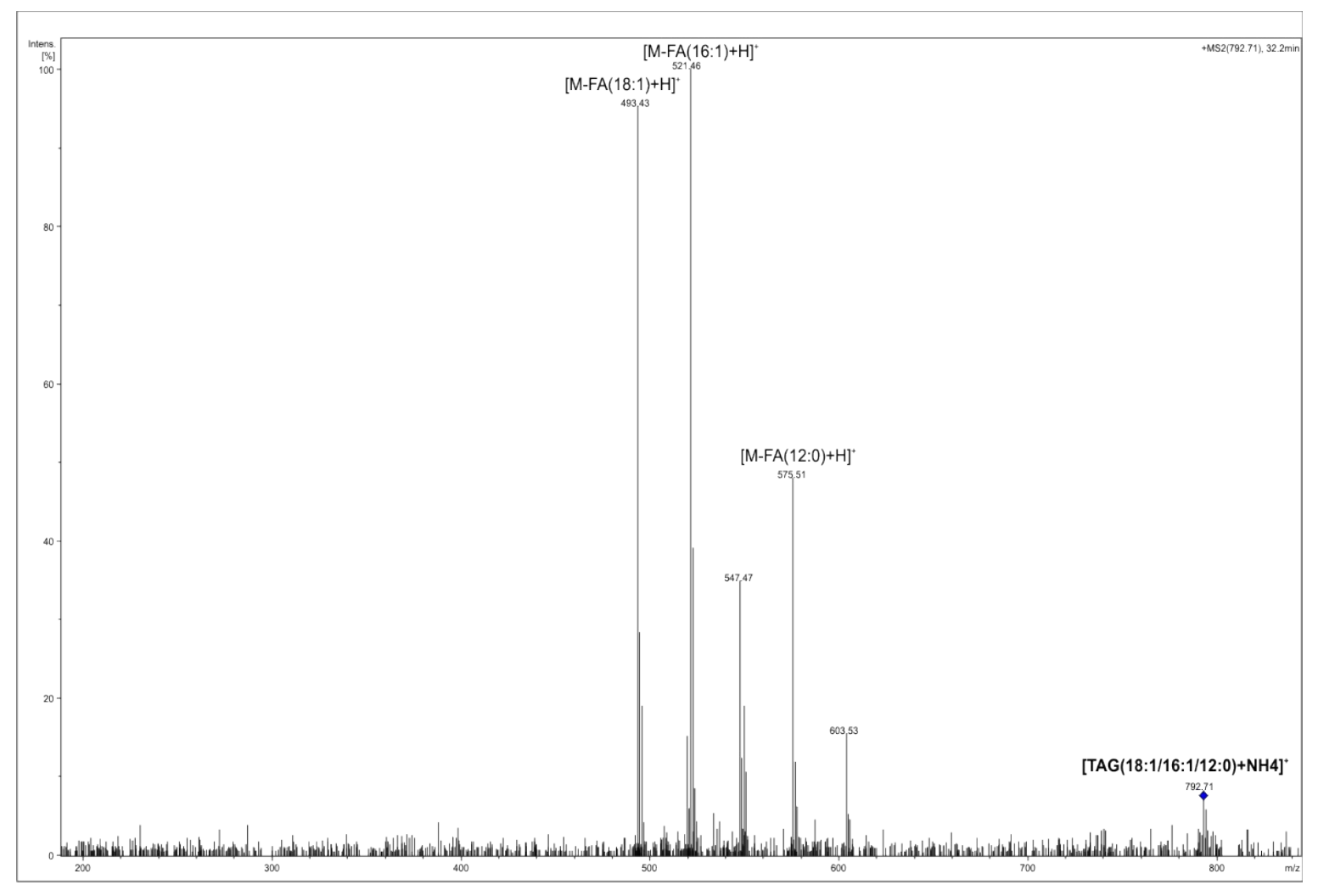

Fig. S6: MS/MS spectrum of TAG(18:1/16:1/12:0) in adipose tissue obtained using positive ionization mode 


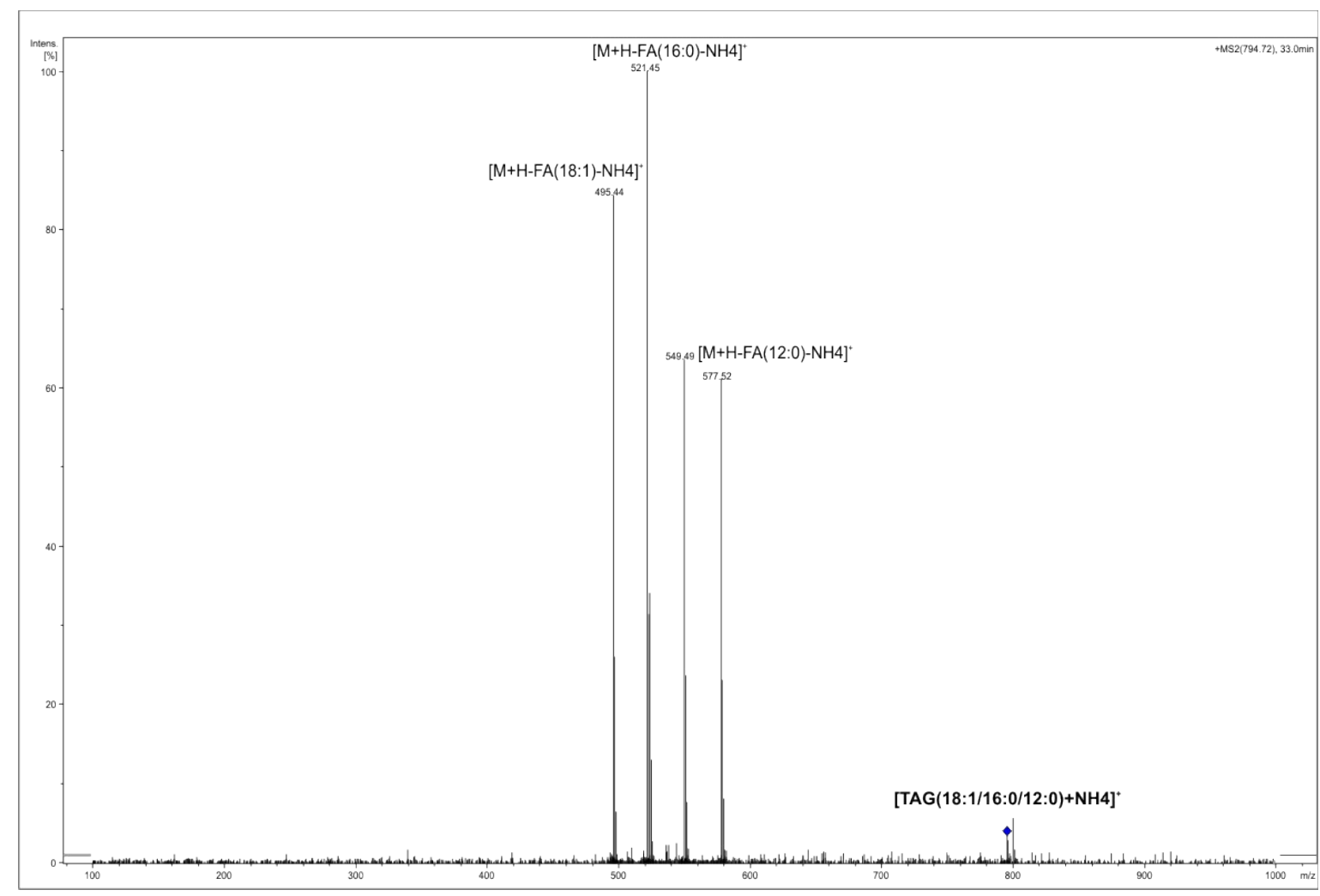

Fig. S7: MS/MS spectrum of TAG(18:1/16:0/12:0) in adipose tissue obtained using positive ionization mode

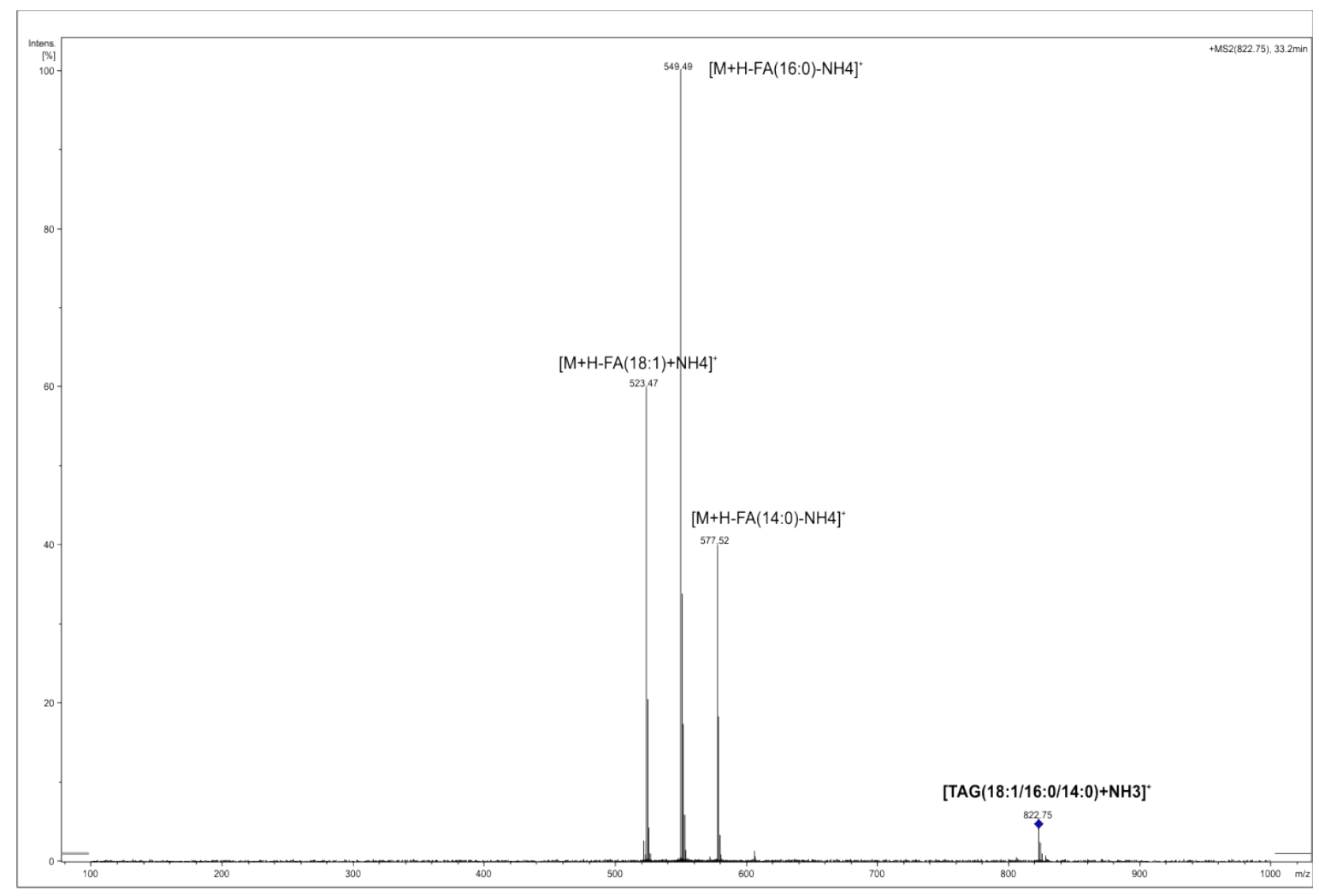

Fig. S8: MS/MS spectrum of TAG(18:1/16:0/14:0) in adipose tissue obtained using positive ionization mode 


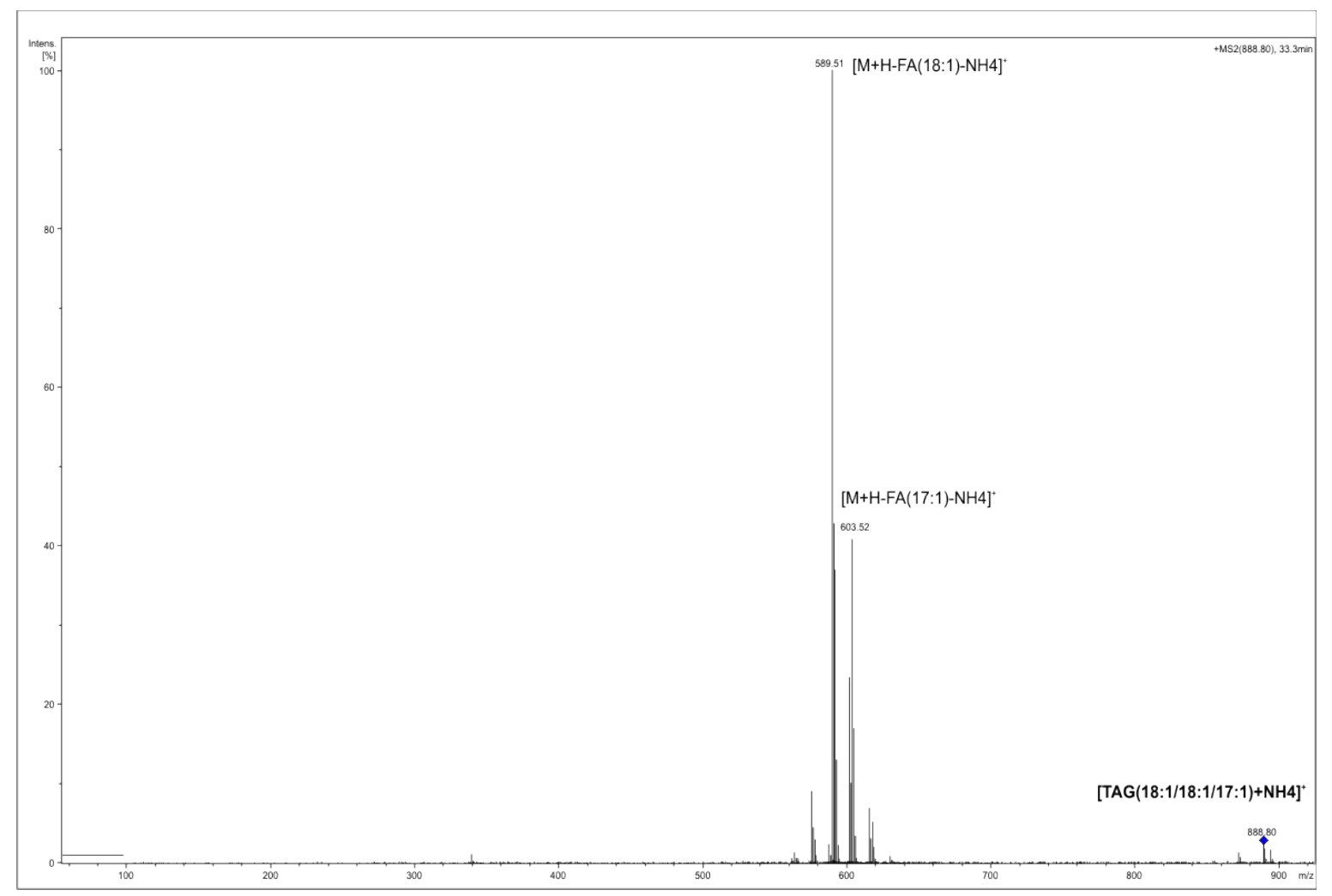

Fig. S9: MS/MS spectrum of TAG(18:1/18:1/17:1) in adipose tissue obtained using positive ionization mode

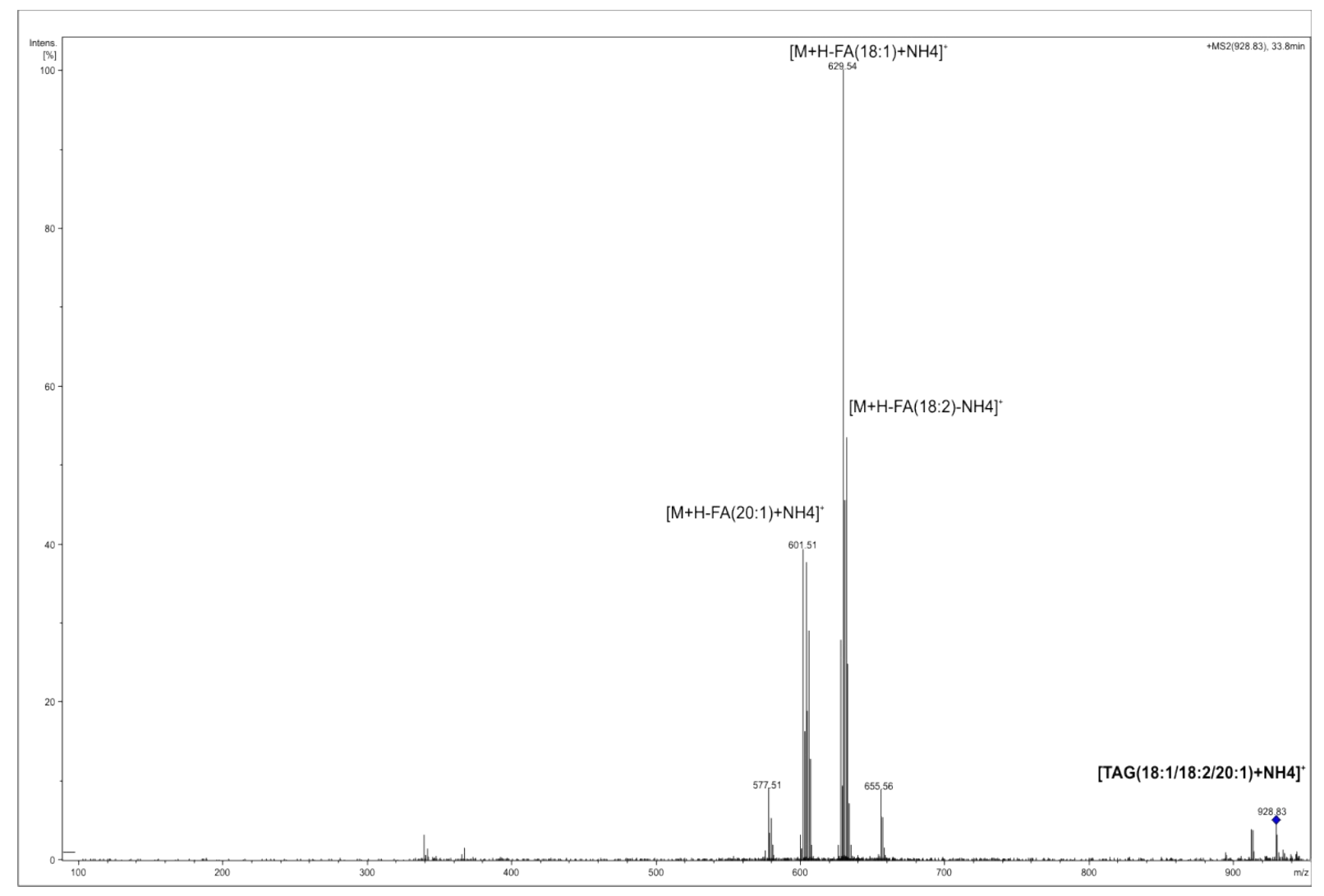

Fig. S10: MS/MS spectrum of TAG(18:1/18:2/20:1) in adipose tissue obtained using positive ionization mode 


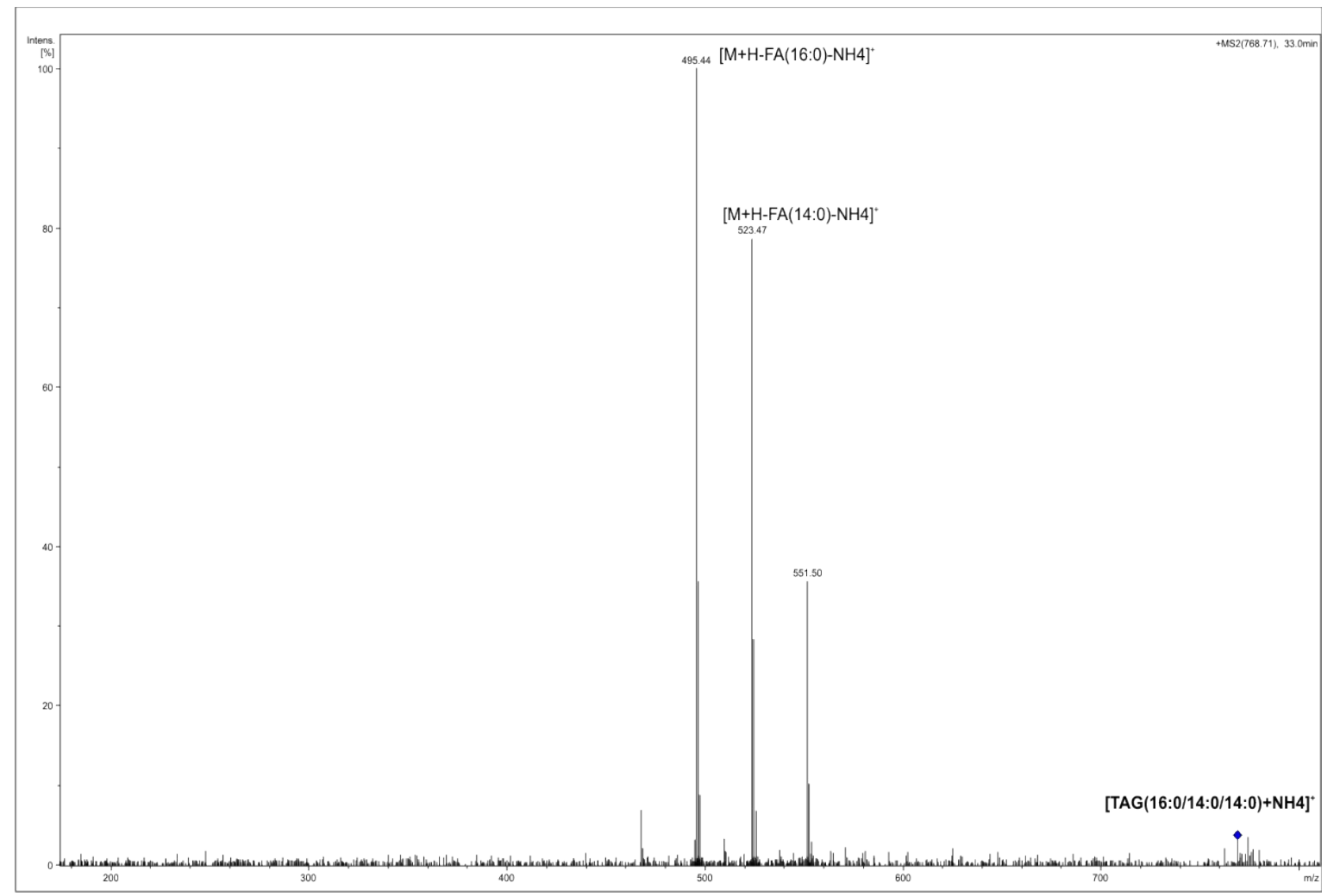

Fig. S11: MS/MS spectrum of TAG(16:0/14:0/14:0) in adipose tissue obtained using positive ionization mode

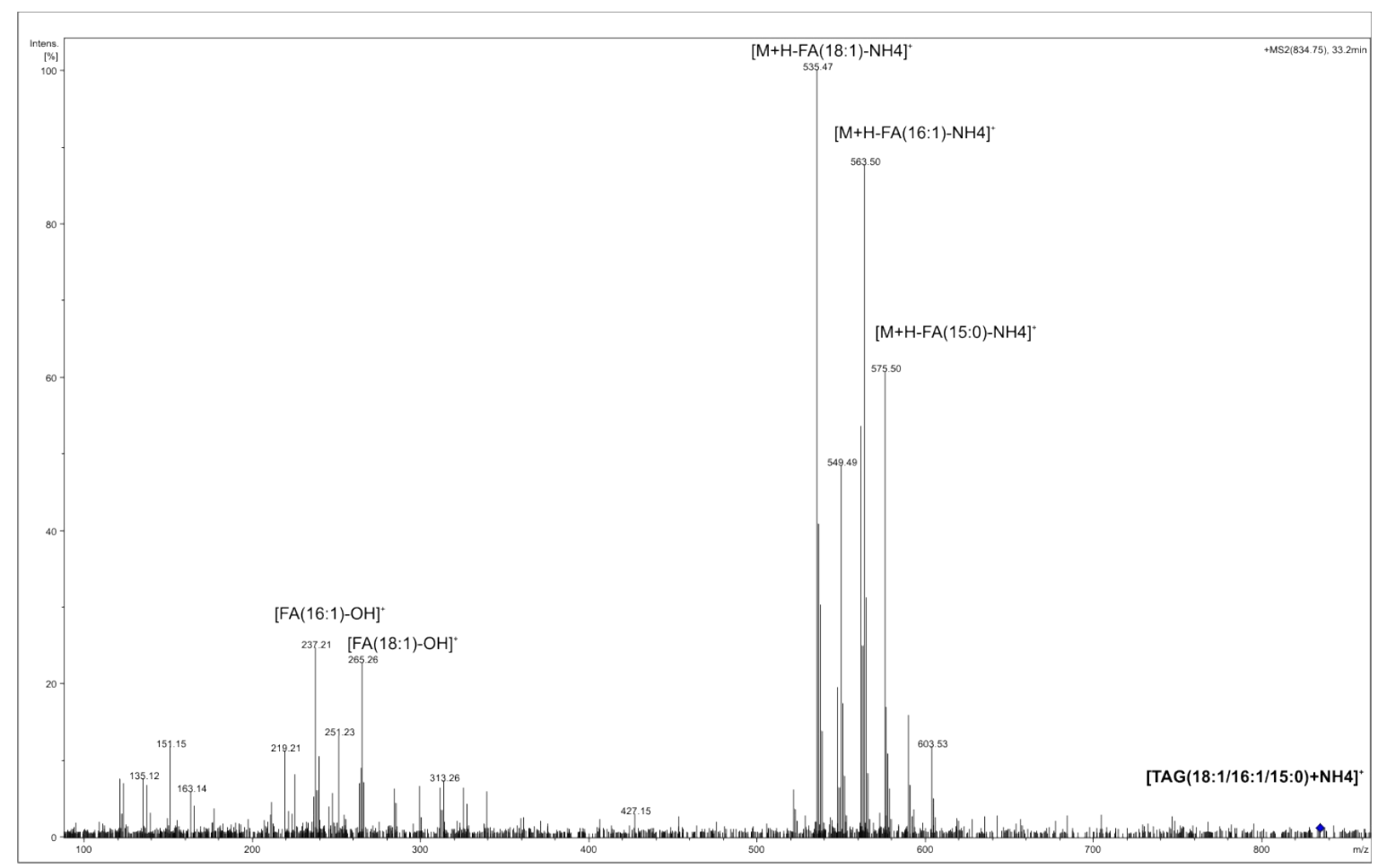

Fig. S12: MS/MS spectrum of TAG(16:1/18:1/15:0) in adipose tissue obtained using positive ionization mode 


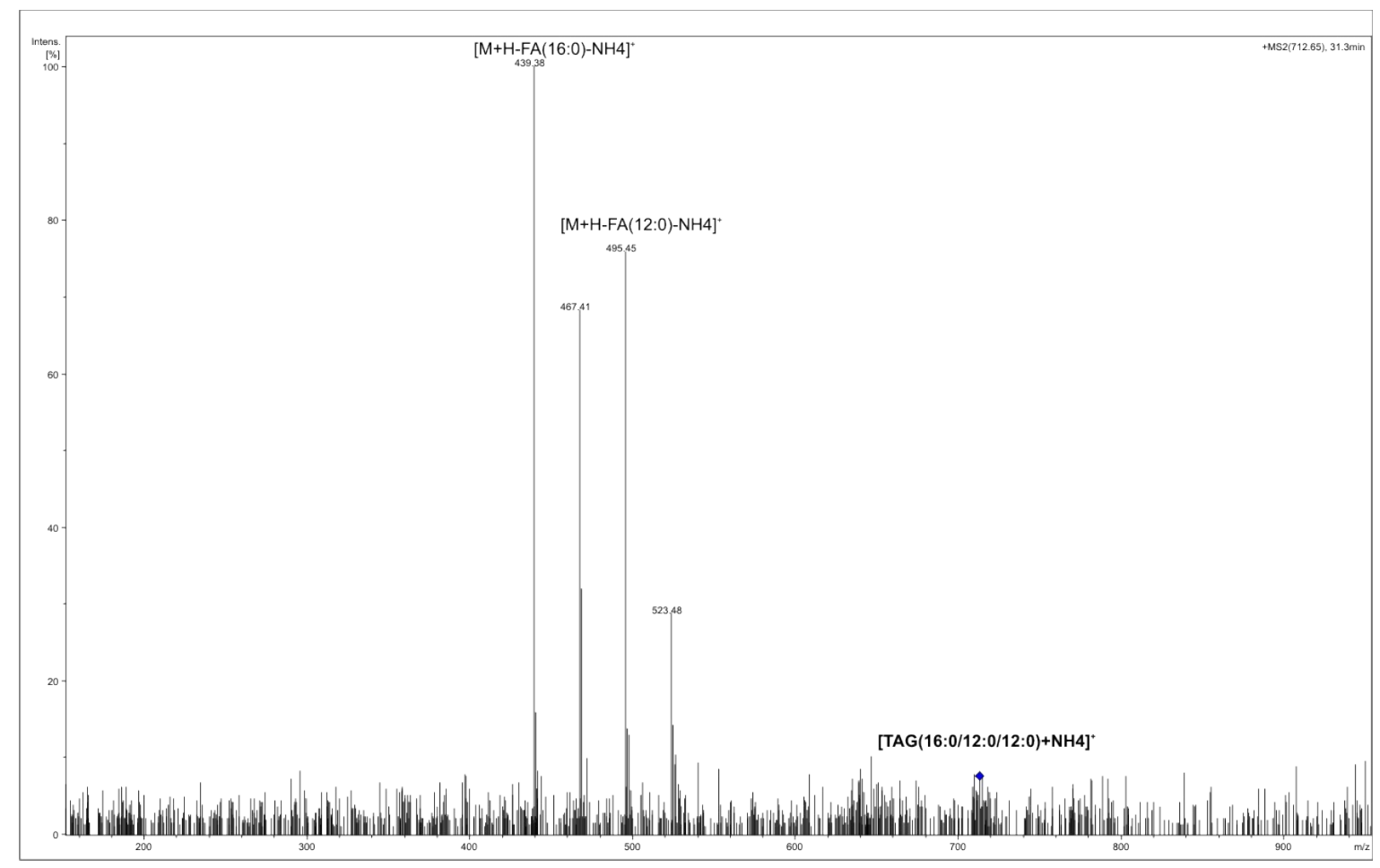

Fig. S13: MS/MS spectrum of TAG(16:0/12:0/12:0) in adipose tissue obtained using positive ionization mode

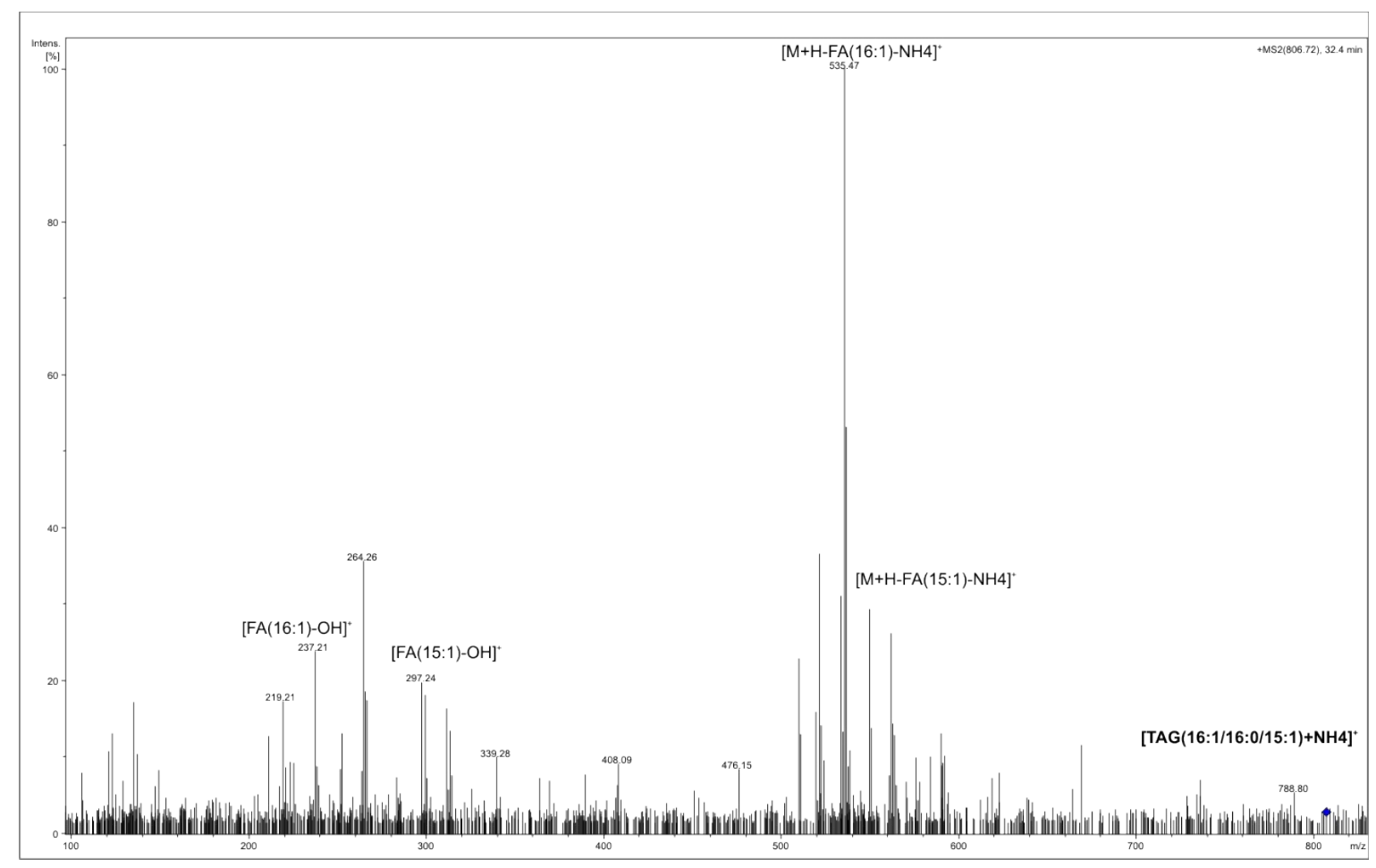

Fig. S14: MS/MS spectrum of TAG(16:1/16:0/15:1) in adipose tissue obtained using positive ionization mode 


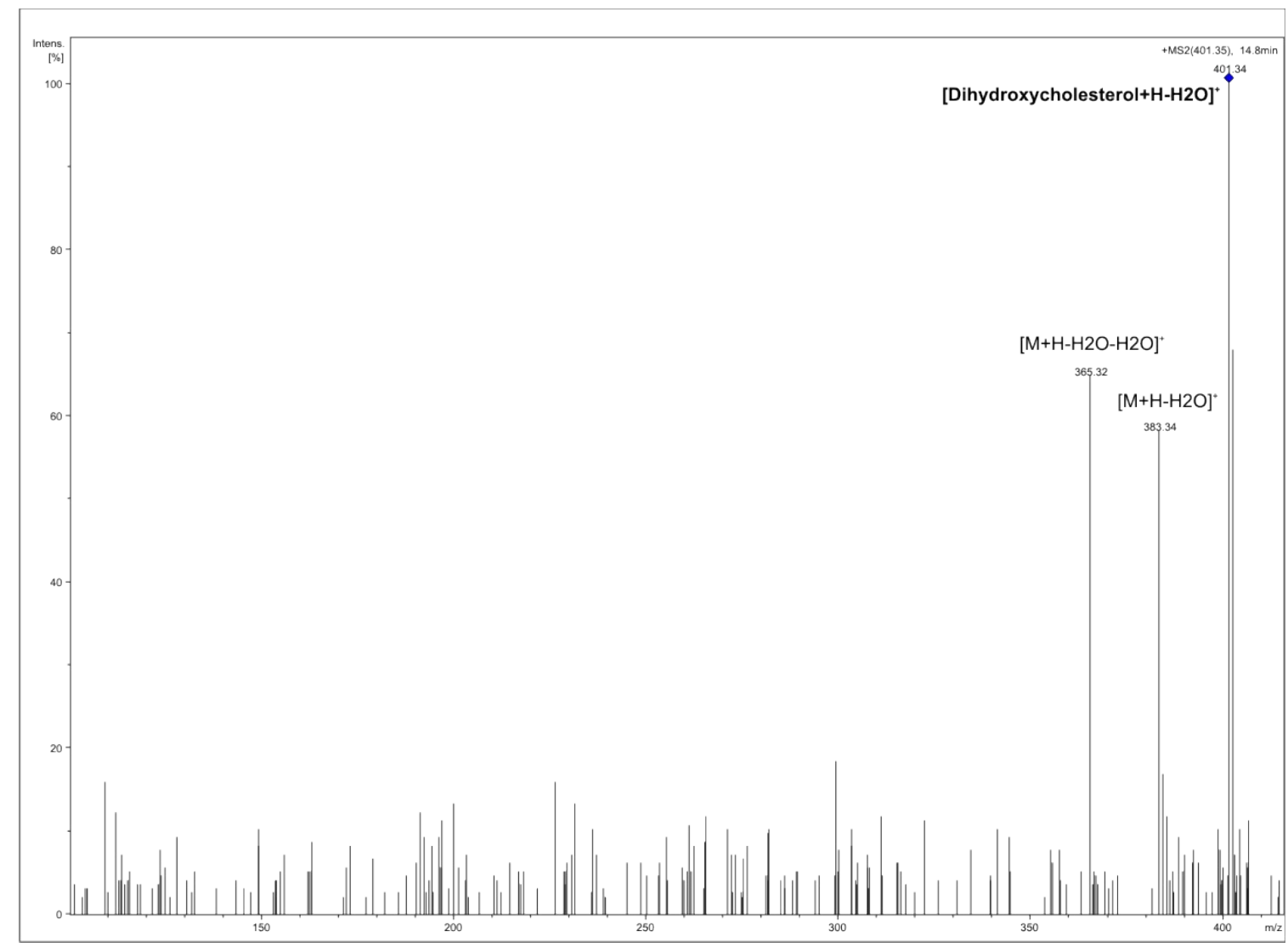

Fig. S15: MS/MS spectrum of dihydroxycholesterol in adipose tissue obtained using positive ionization mode

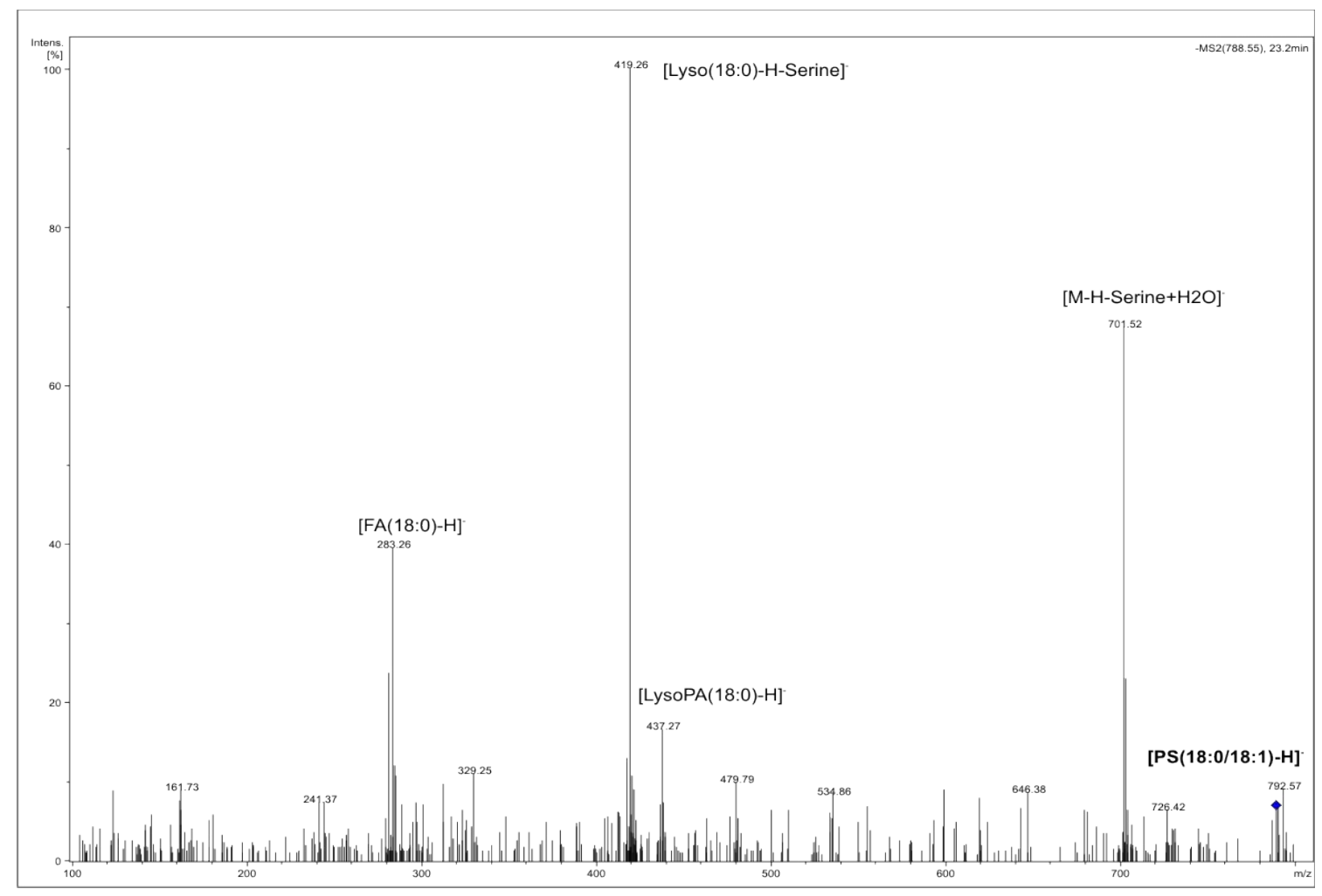

Fig. S16: MS/MS spectrum of PS(18:0/18:1) in adipose tissue obtained using negative ionization mode 


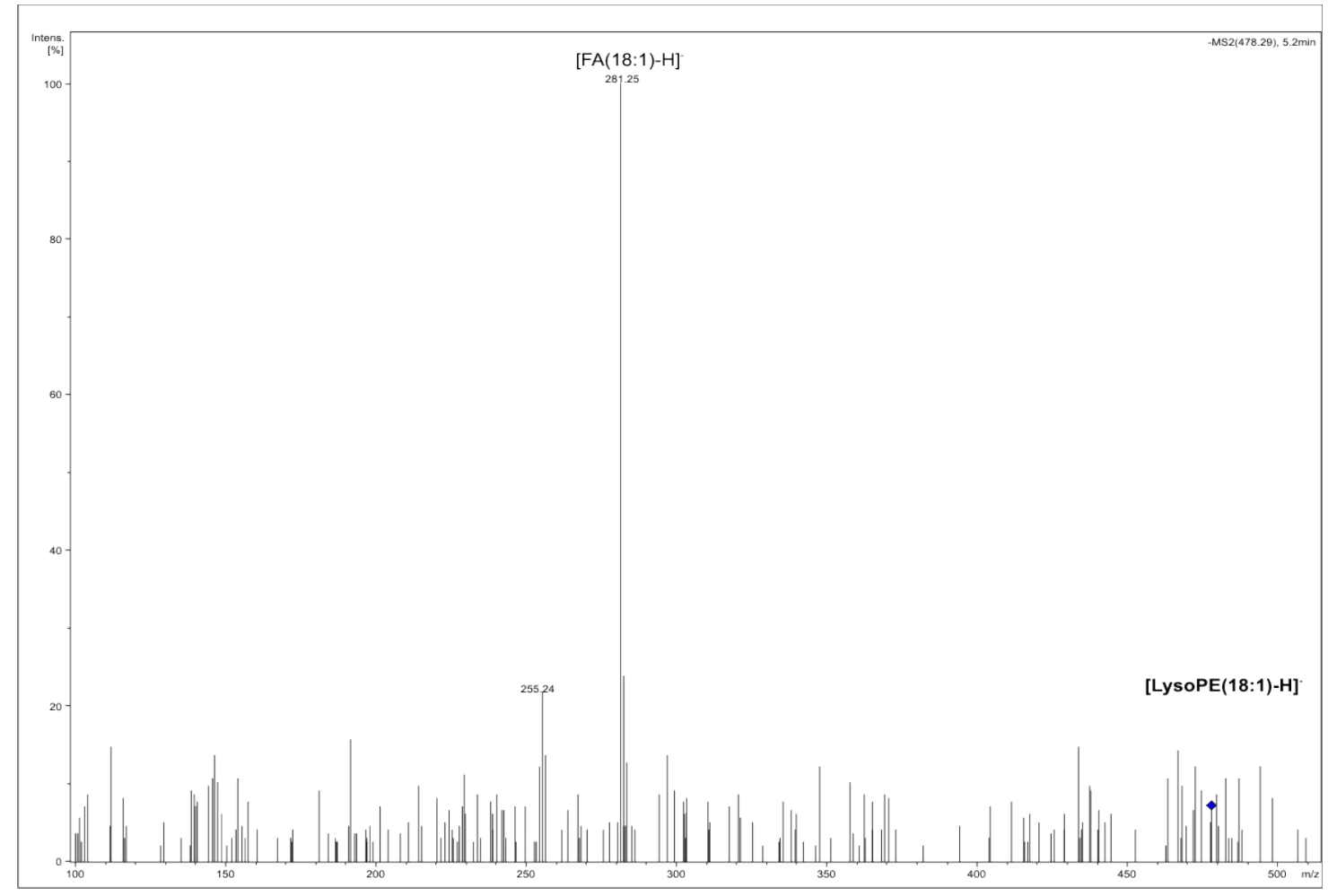

Fig. S17: MS/MS spectrum of LysoPE(18:1) in adipose tissue obtained using negative ionization mode

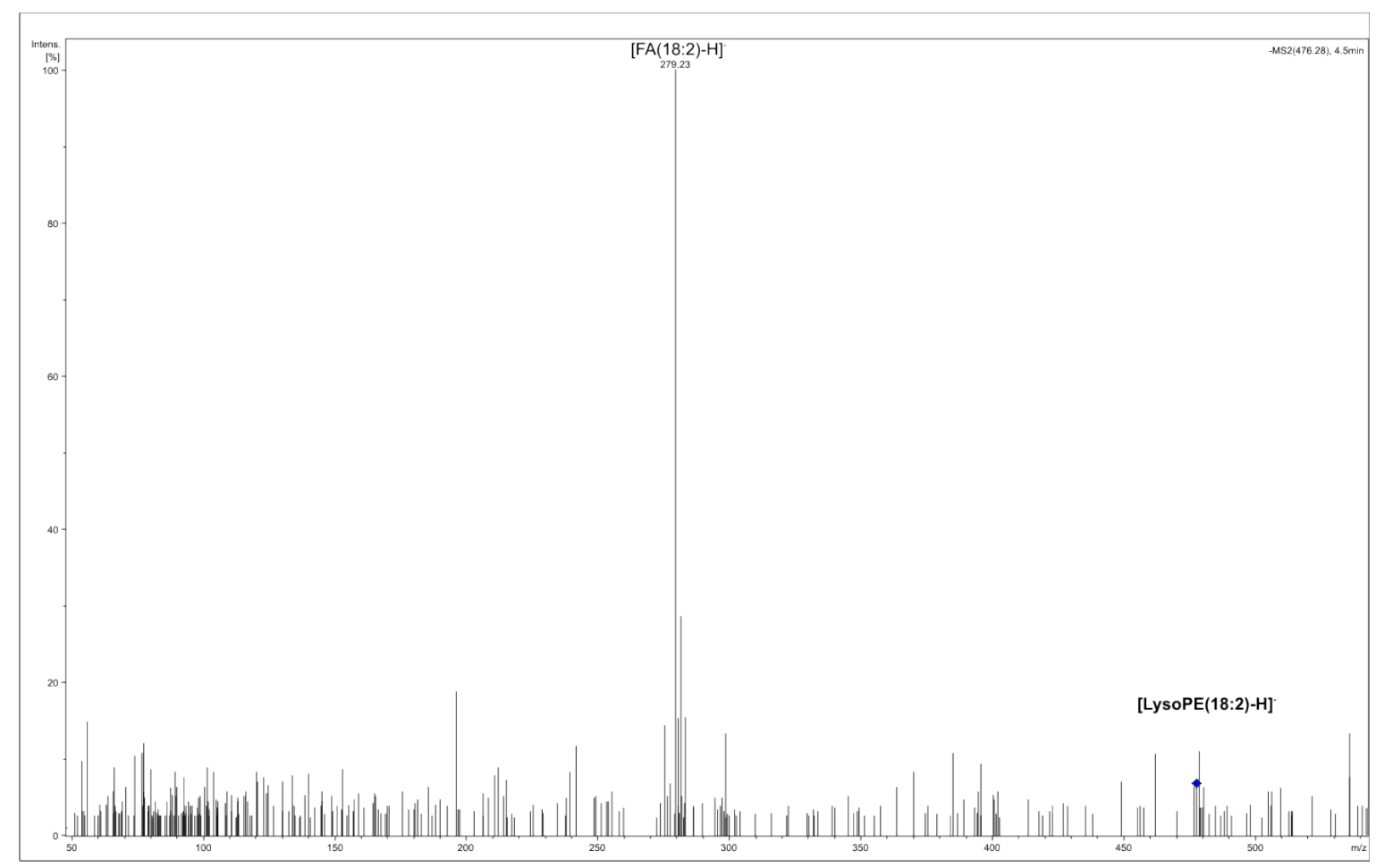

Fig. S18: MS/MS spectrum of LysoPE(18:2) in adipose tissue obtained using negative ionization mode 


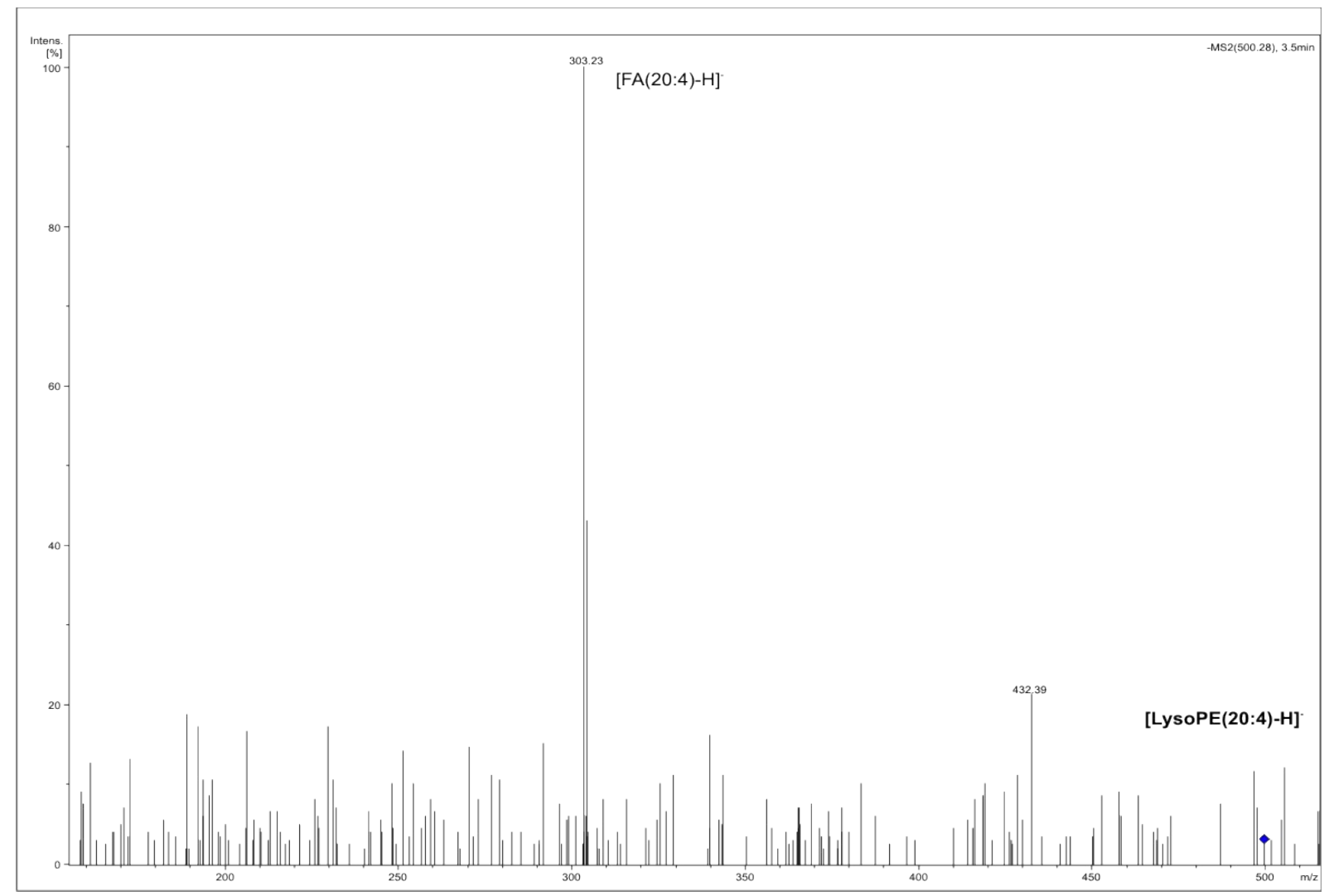

Fig. S19: MS/MS spectrum of LysoPE(20:4) in adipose tissue obtained using negative ionization mode

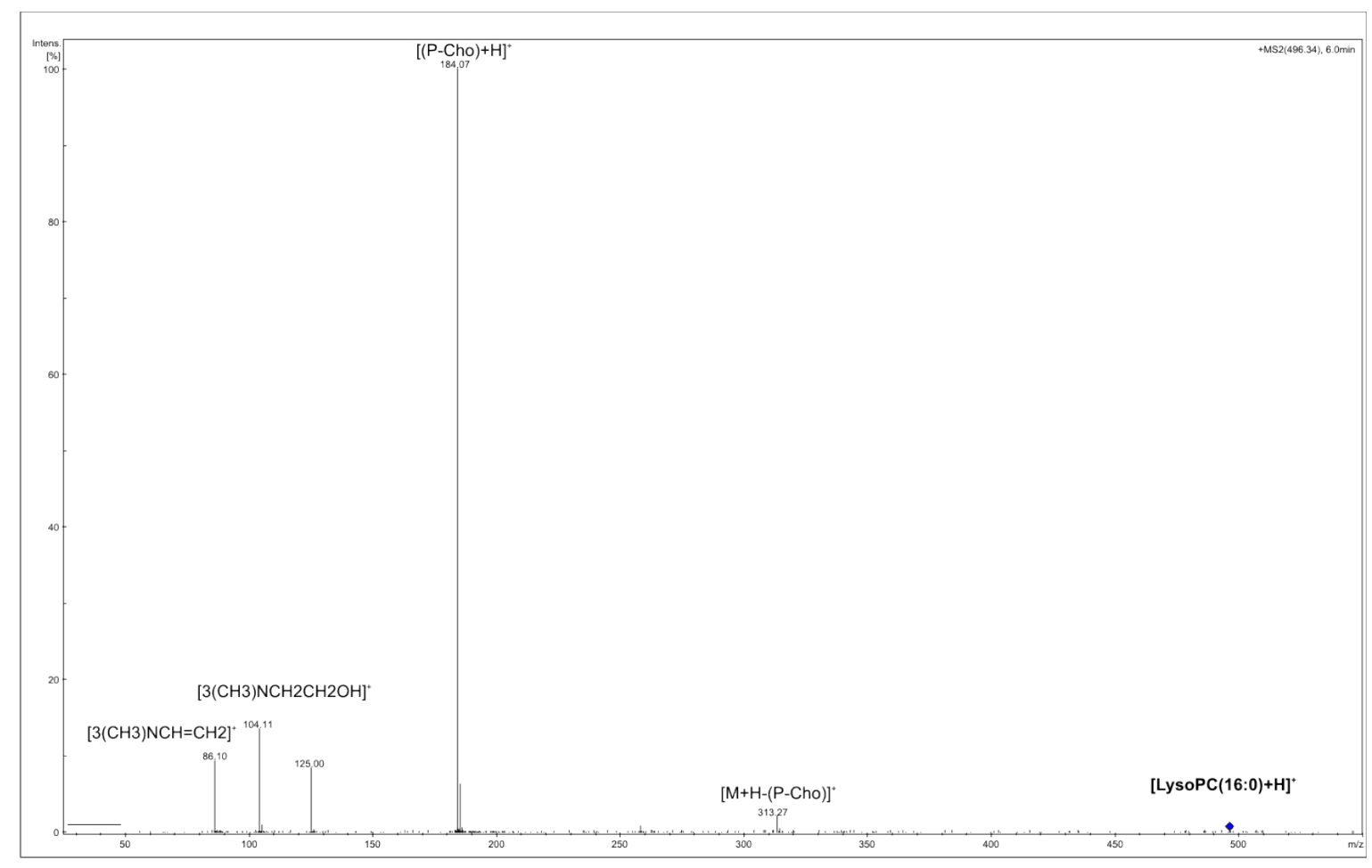

Fig. S20: MS/MS spectrum of LysoPC(16:0) in adipose tissue obtained using positive ionization mode 


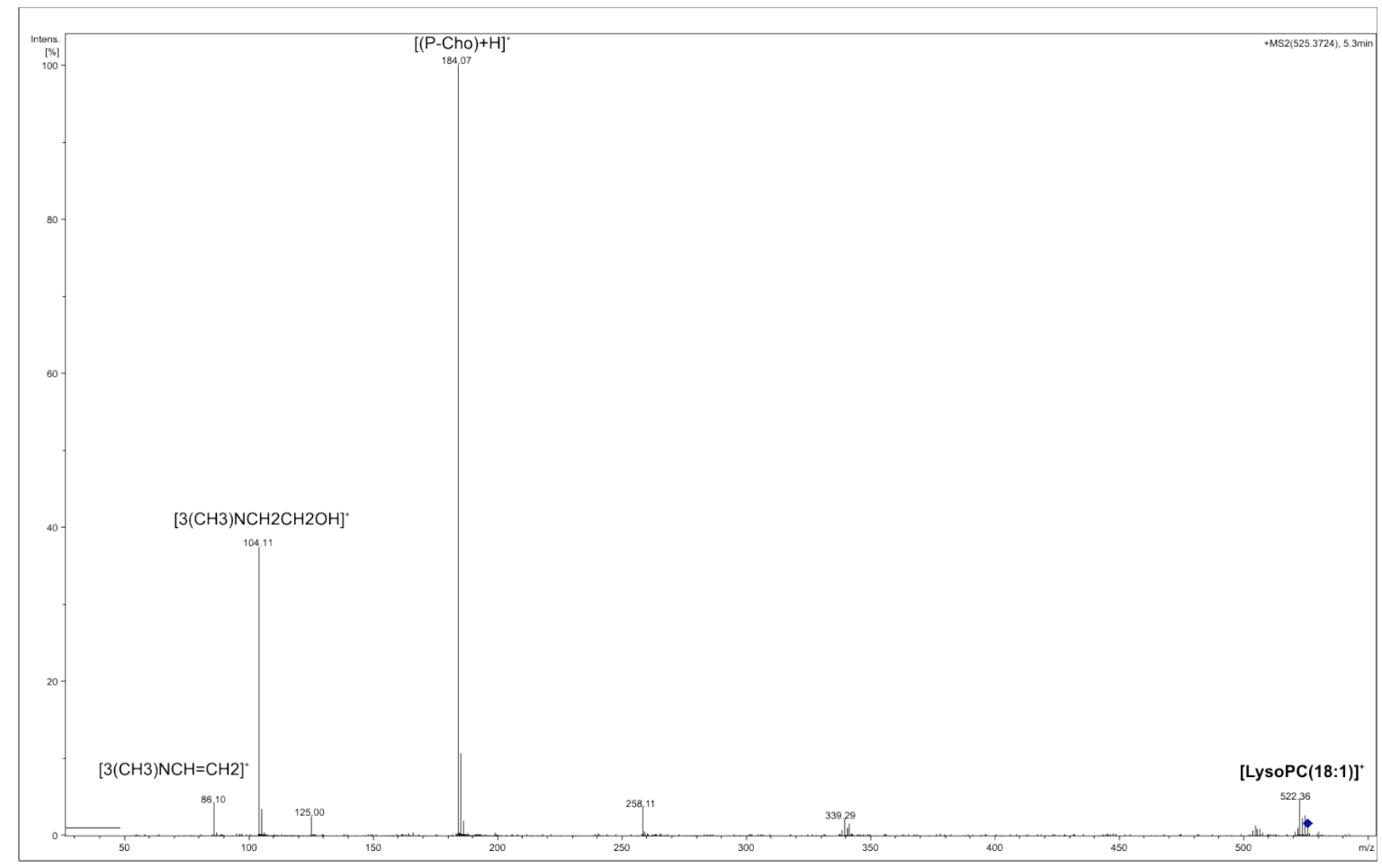

Fig. S21: MS/MS spectrum of LysoPC(18:1) in adipose tissue obtained using positive ionization mode

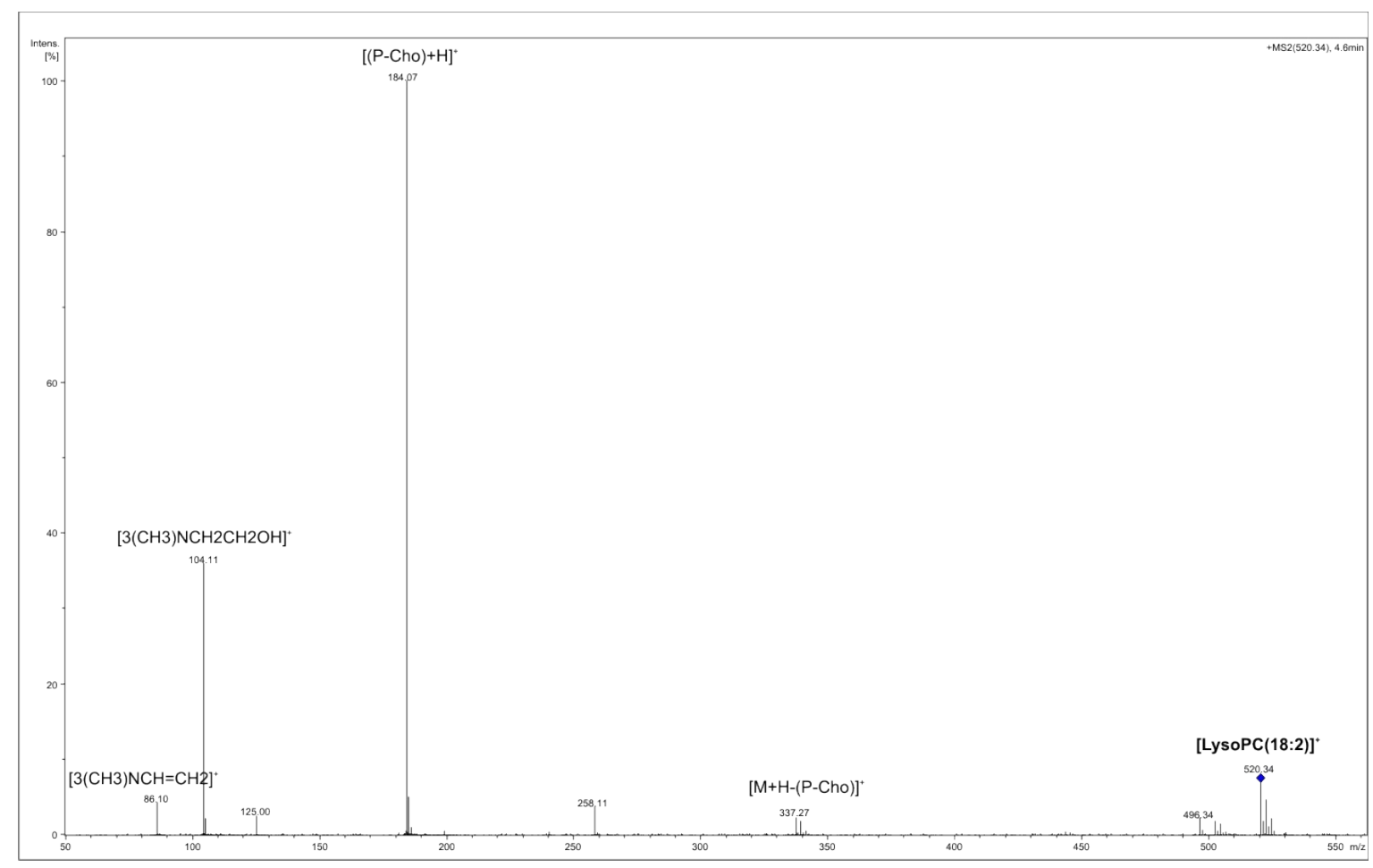

Fig. S22: MS/MS spectrum of LysoPC(18:2) in adipose tissue obtained using positive ionization mode 


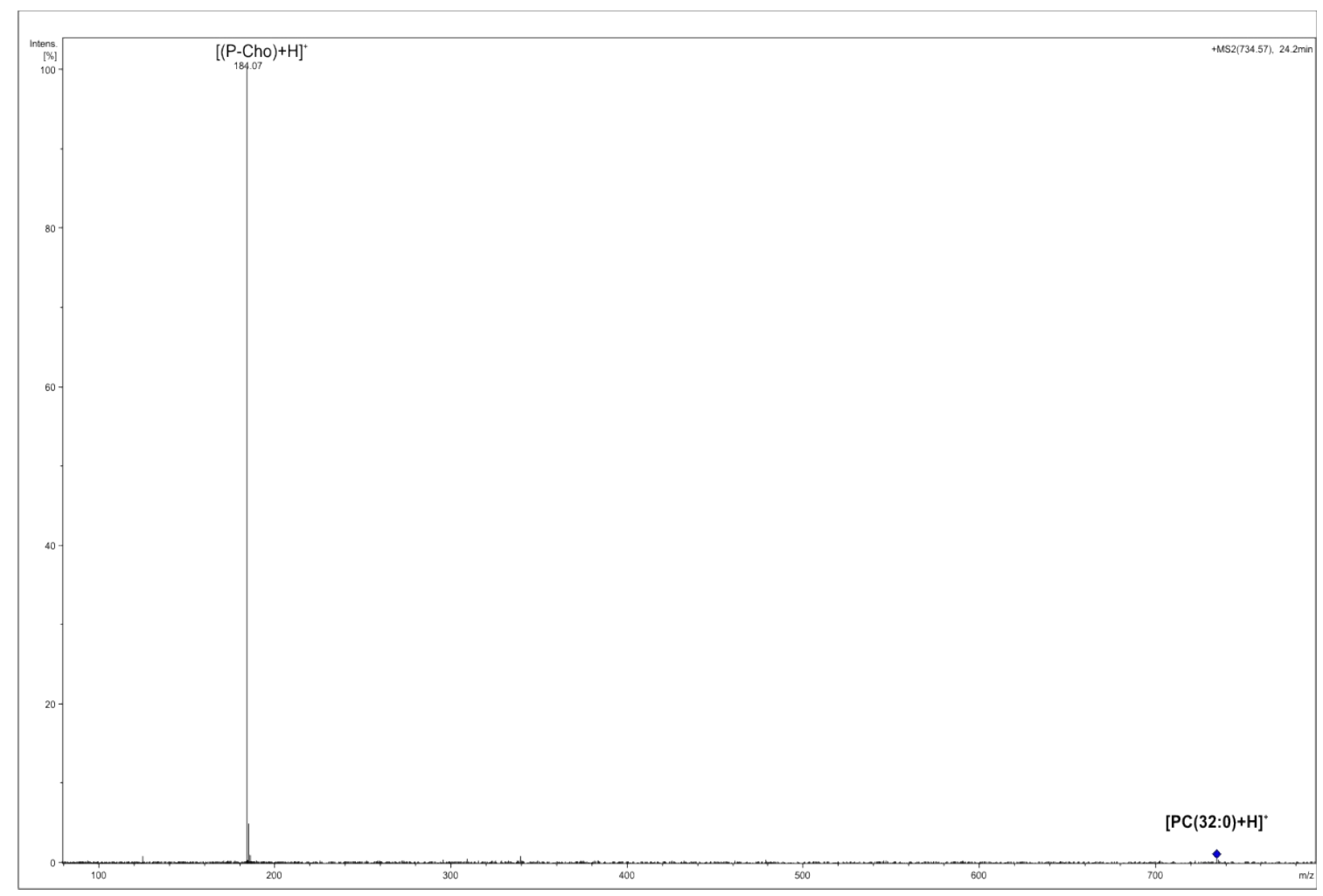

Fig. S23: MS/MS spectrum of $\mathrm{PC}(32: 0)$ in adipose tissue obtained using positive ionization mode

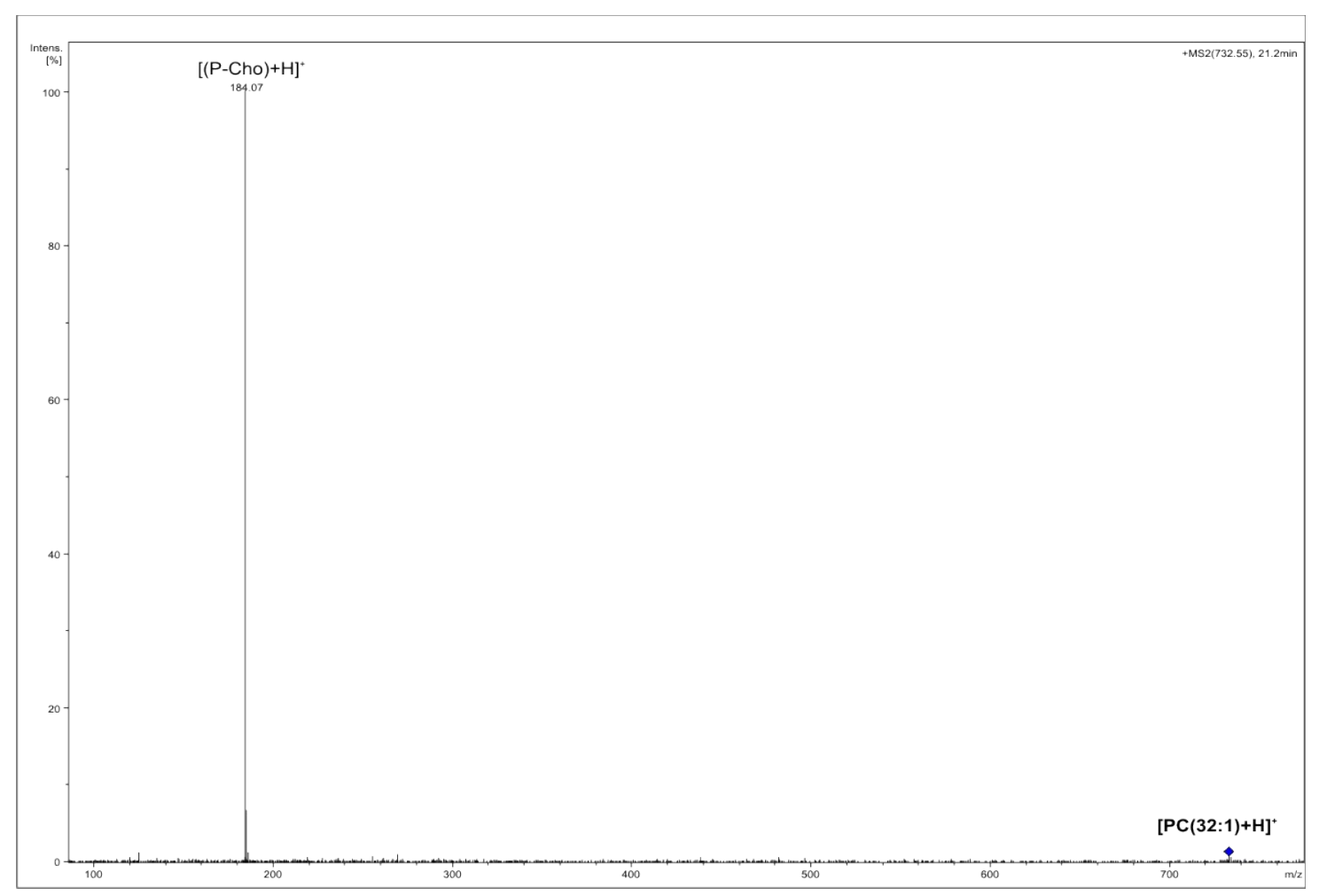

Fig. S24: MS/MS spectrum of $\mathrm{PC}(32: 1)$ in adipose tissue obtained using positive ionization mode 


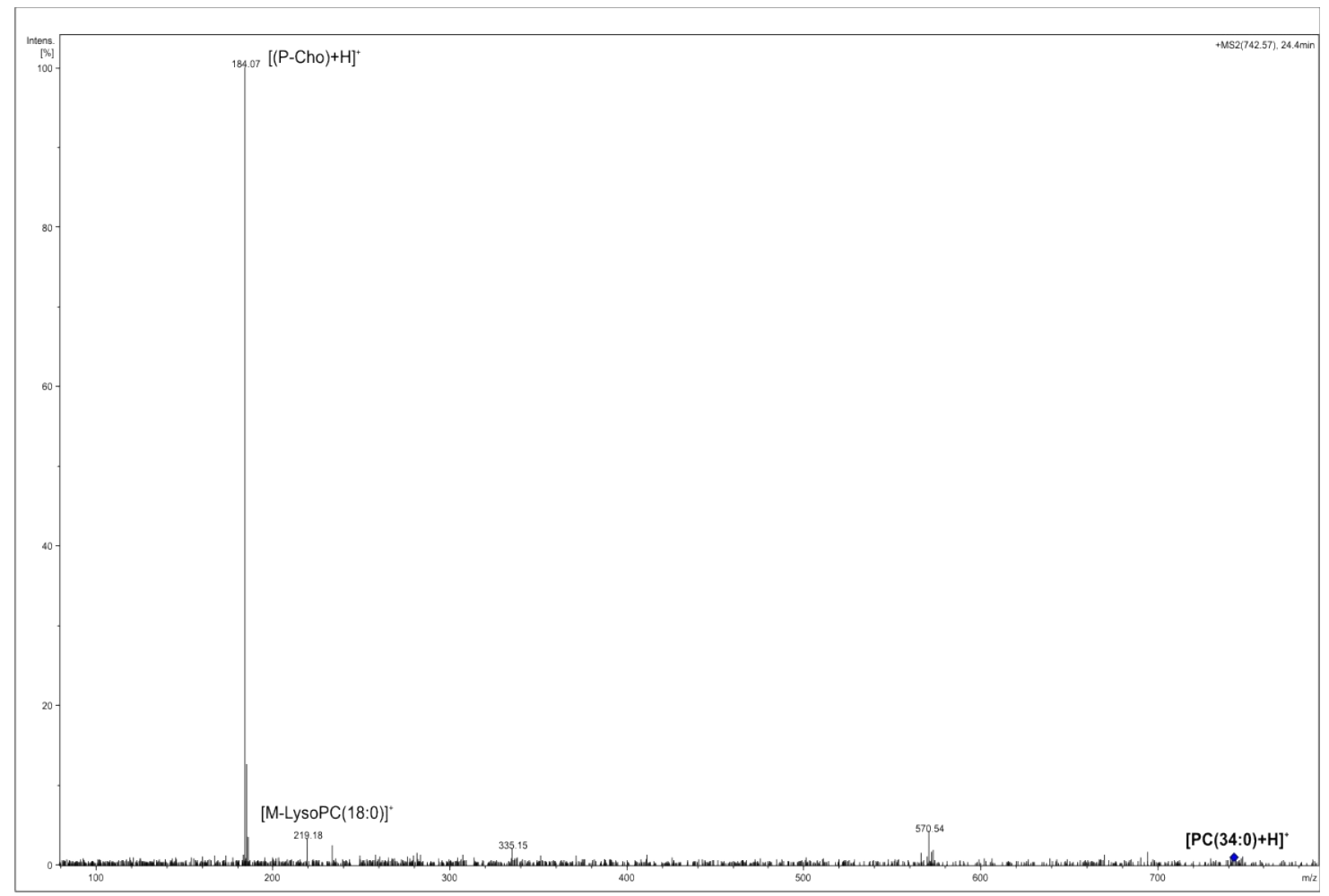

Fig. S25: MS/MS spectrum of $\mathrm{PC}(34: 0)$ in adipose tissue obtained using positive ionization mode

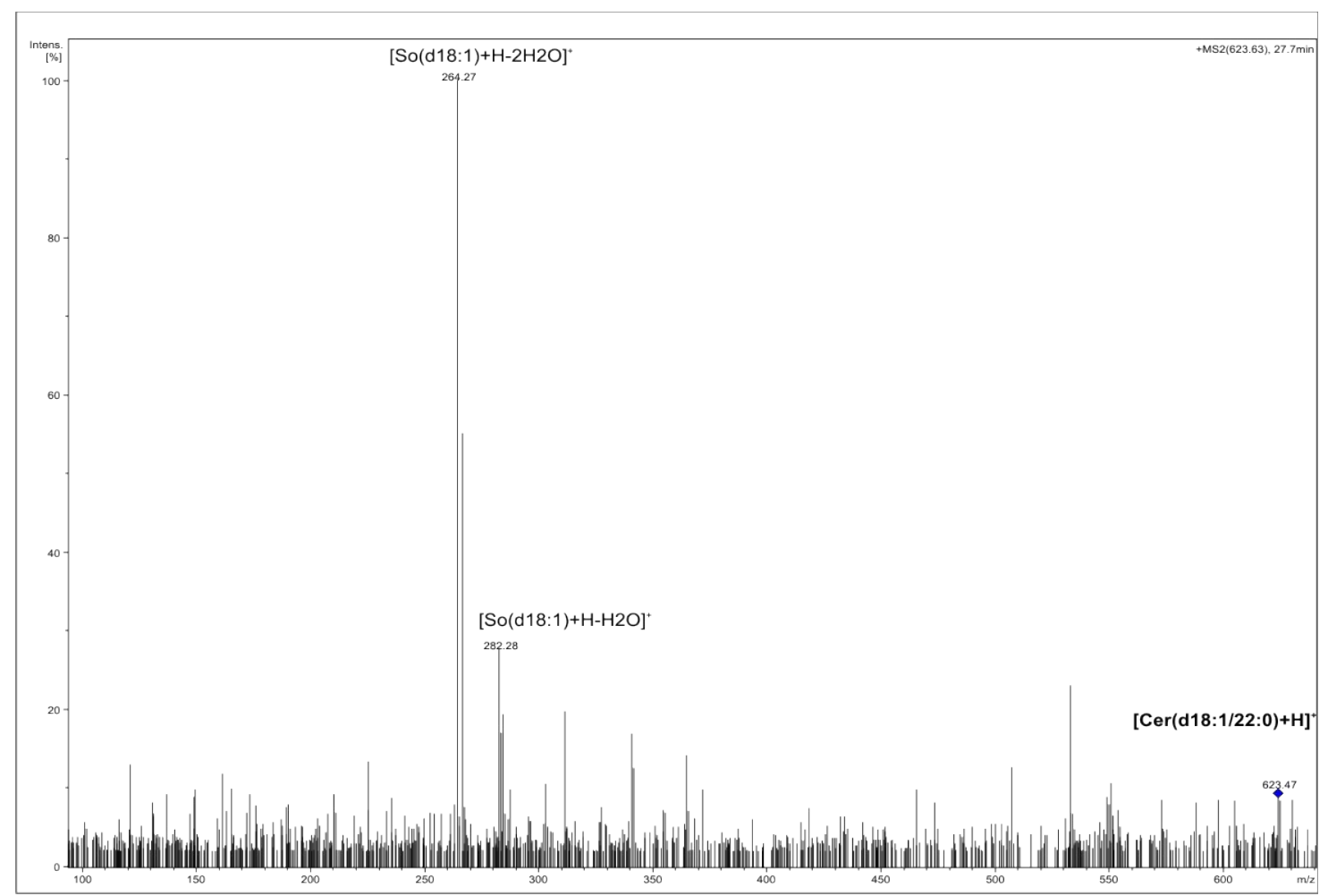

Fig. S26: MS/MS spectrum of Cer(d18:1/22:0) in adipose tissue obtained using positive ionization mode 


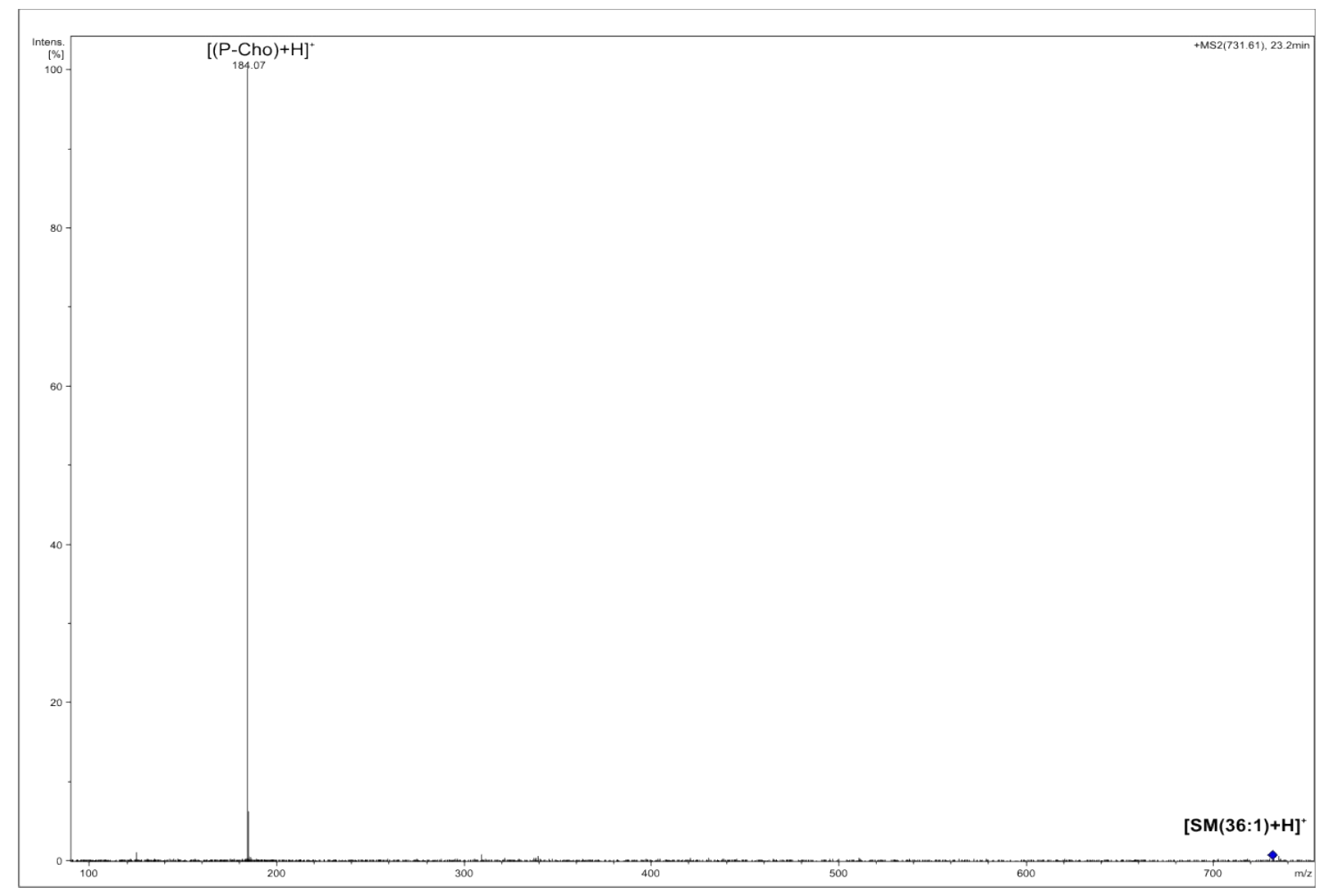

Fig. S27: MS/MS spectrum of SM(36:1) in adipose tissue obtained using positive ionization mode

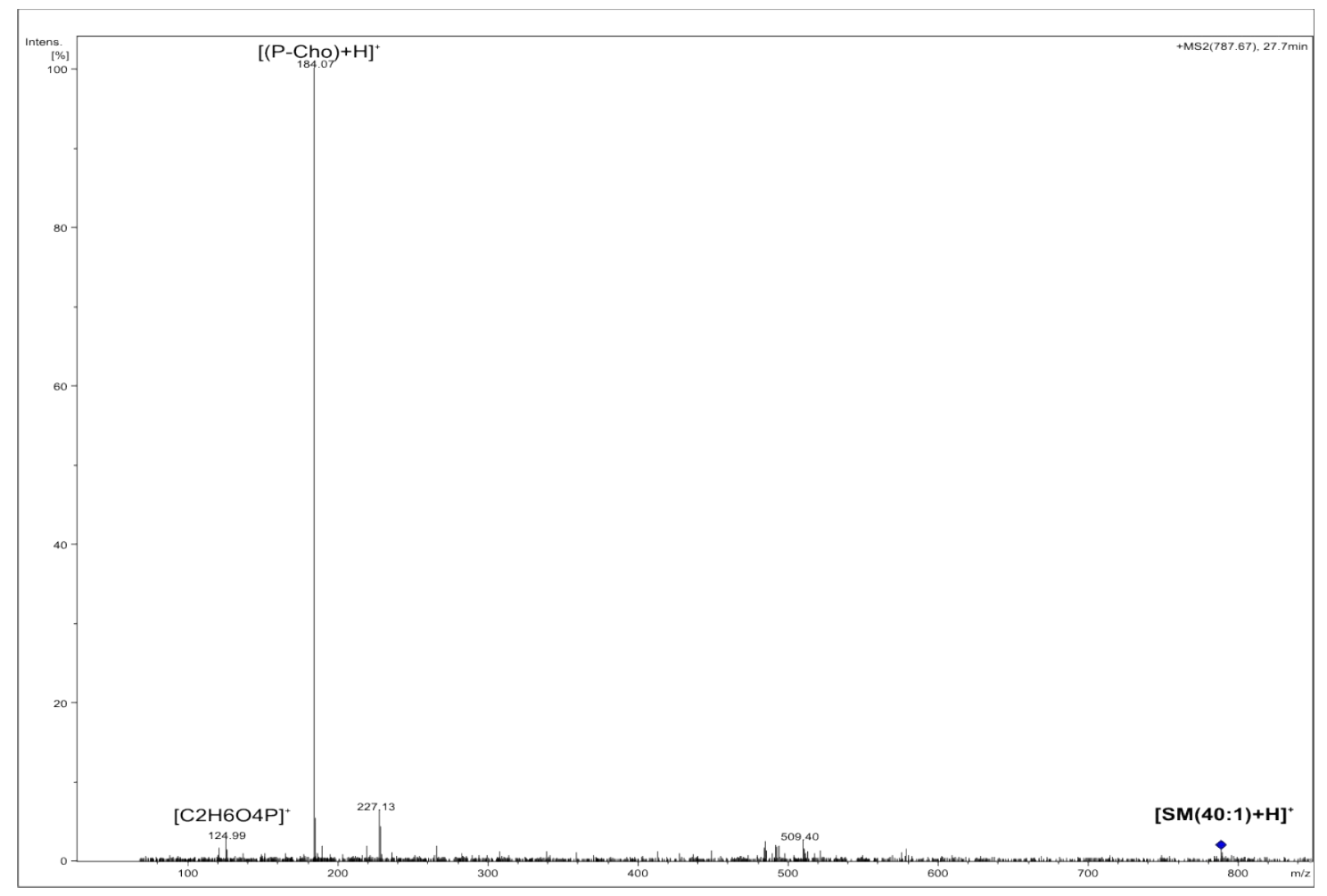

Fig. S28: MS/MS spectrum of SM(40:1) in adipose tissue obtained using positive ionization mode 


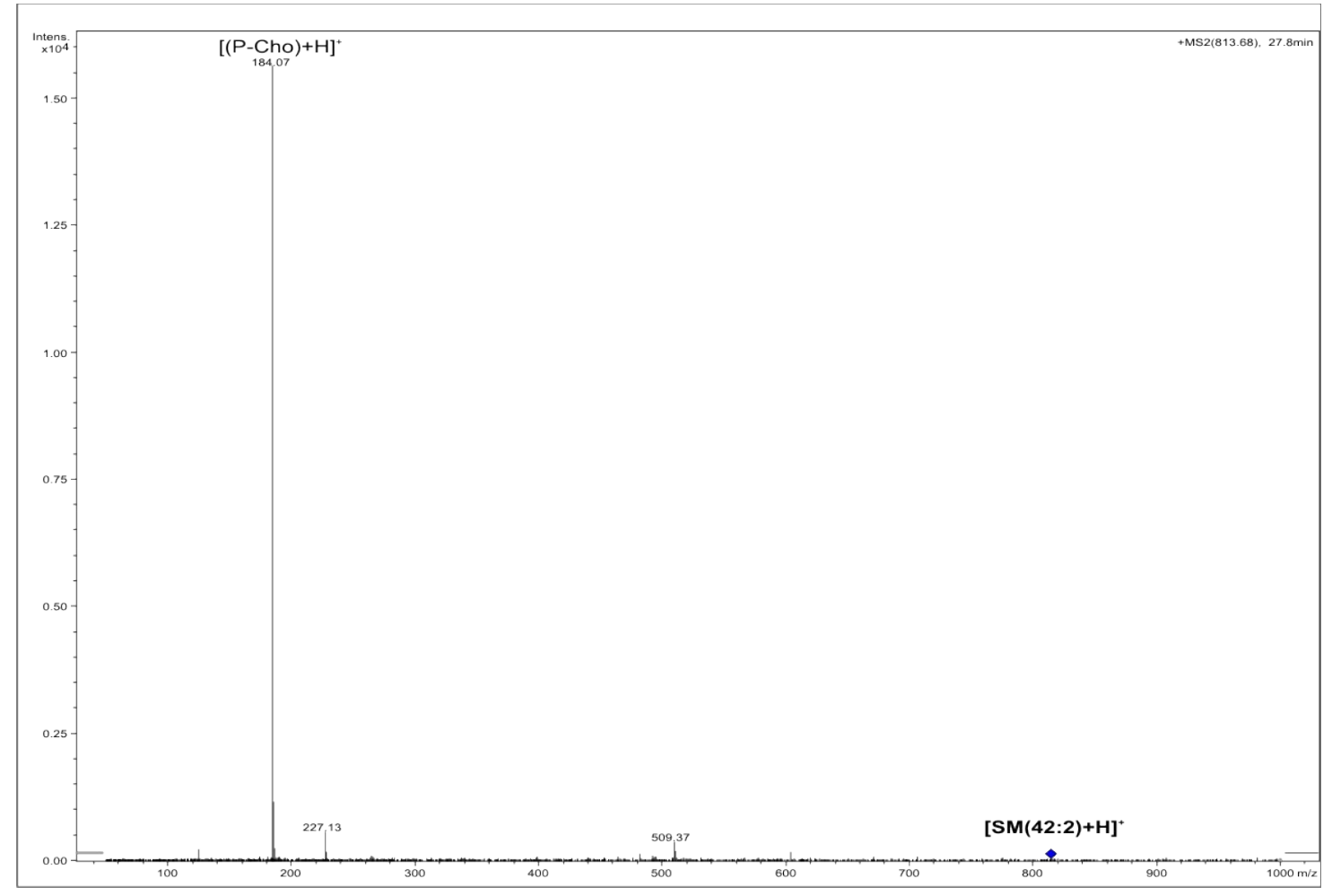

Fig. S29: MS/MS spectrum of SM(42:2) in adipose tissue obtained using positive ionization mode

A

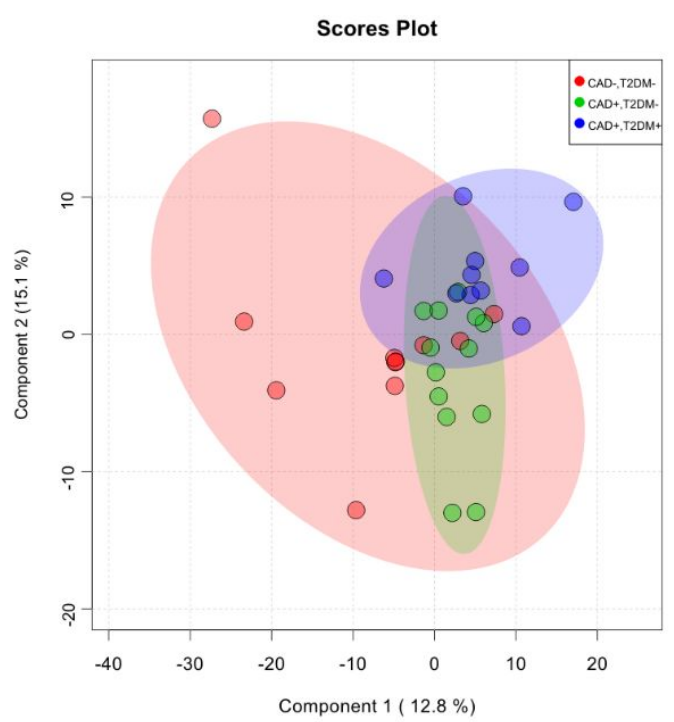

C
B

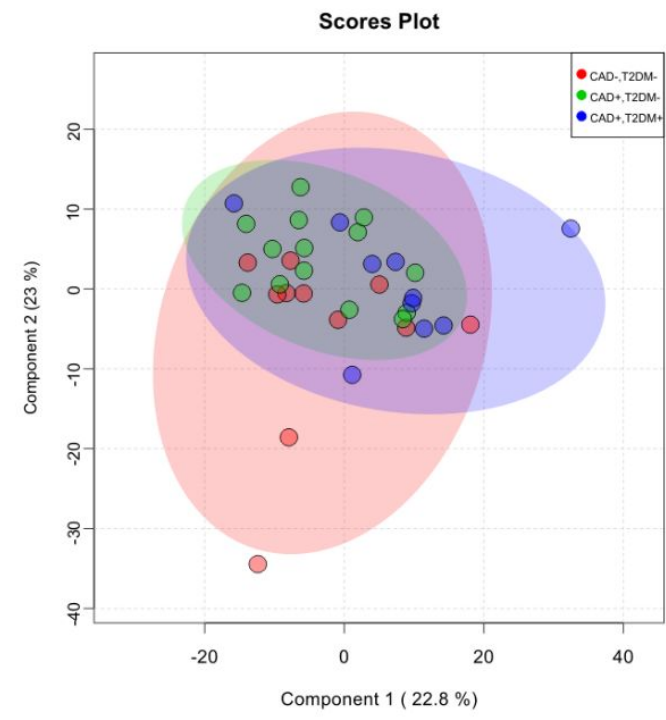

D 

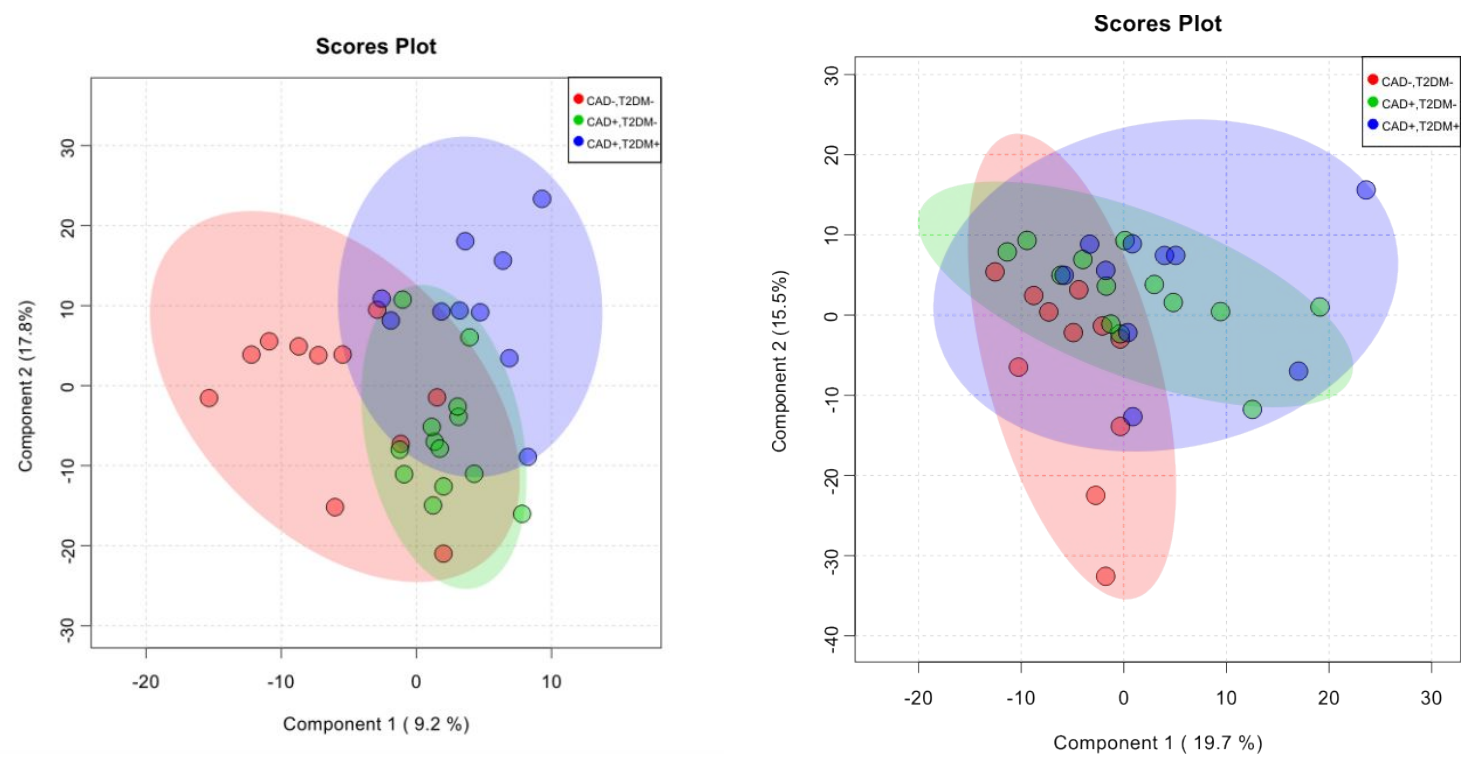

Fig. S30 PLS-DA scores plot for SAT A) Positive ionization mode - untargeted lipidomics (the results of cross validation for 3 components: accuracy: $0.62, R 2=0.667, Q 2=-0.399$, and $p$ value of permutation test $=0.283$ for 2000 repetitions), B) Negative ionization mode untargeted lipidomics (the results of cross validation for 3 components: accuracy $=0.57, R 2=$ $0.409, \mathrm{Q} 2=-0.936, \mathrm{p}$ value of permutation test $=0.104$ for 2000 repetitions), C) Positive ionization mode - minor lipids (the results of cross validation for 2 components: accuracy= $0.47, \mathrm{R} 2=0.630, \mathrm{Q} 2=-0.424, \mathrm{p}$ value of permutation test $=0.626$ for 2000 repetitions), $\mathrm{D})$ Negative ionization mode - minor lipids (cross validation results for 3 component: accuracy = $0.411, \mathrm{R} 2=0.523, \mathrm{Q} 2=-0.852, \mathrm{p}$ value of permutation test $<0.001$ for 2000 repetitions); CAD-, T2DM- (red points): without coronary artery disease and without type 2 diabetes mellitus, CAD+, T2DM- (green points): with coronary artery disease and without type 2 diabetes mellitus, $C A D+, T 2 D M+$ (blue points): with both coronary artery disease and type 2 diabetes mellitus 


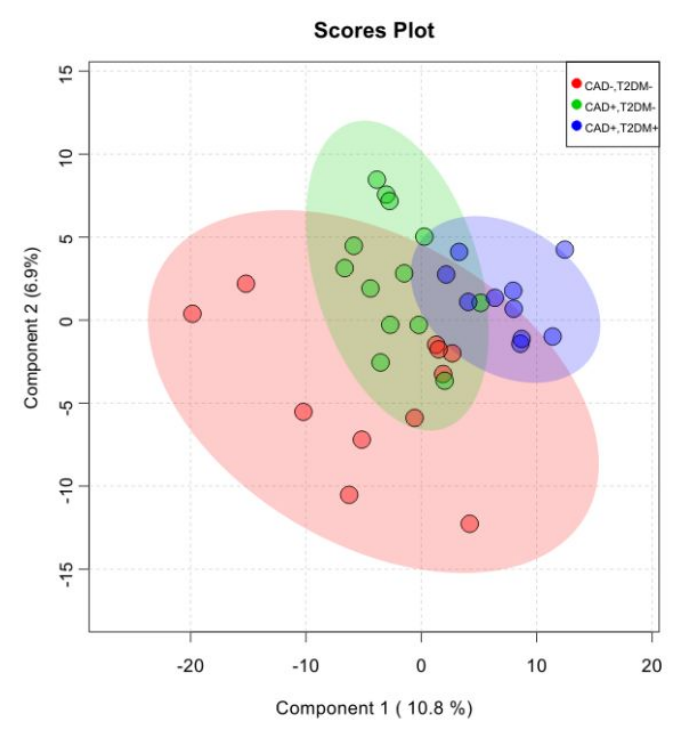

C

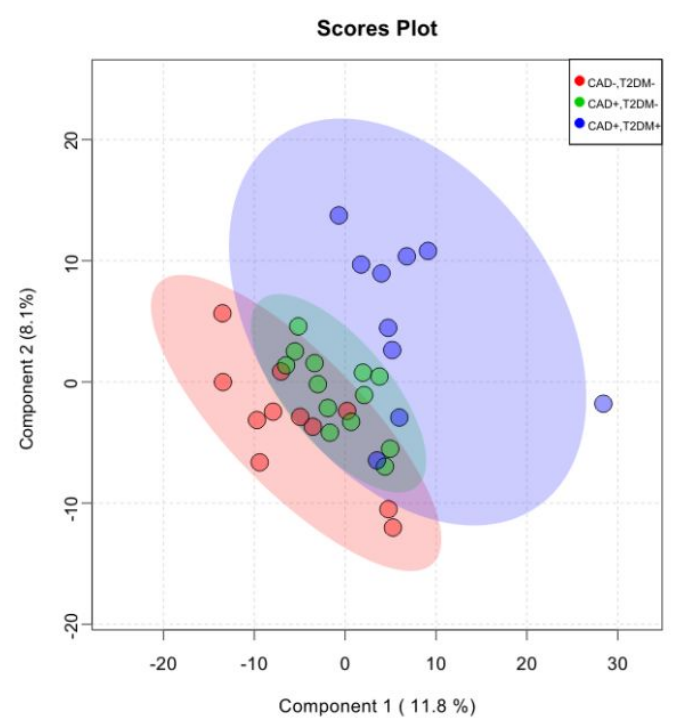

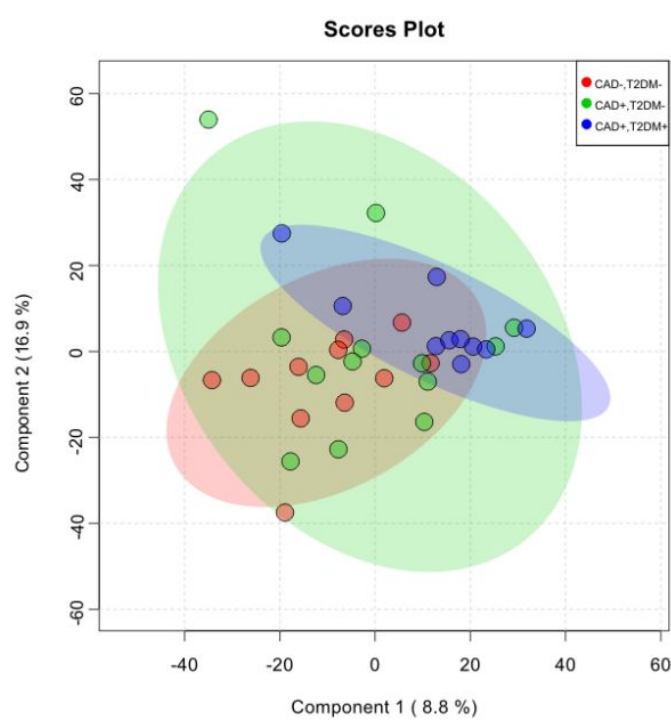

$\mathrm{D}$

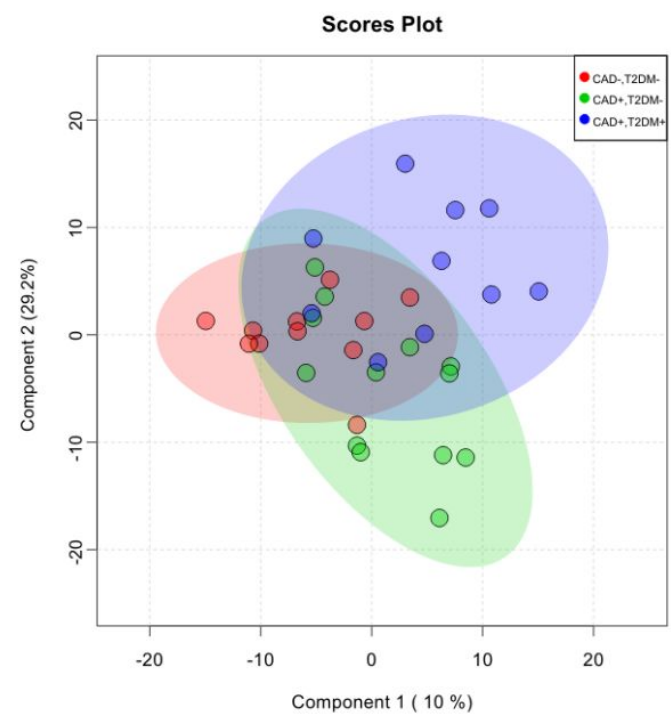

Fig. S31 PLS-DA scores plot for EAT A) Positive ionization mode untargeted lipidomics (the results of cross validation for 2 components: accuracy $=0.53, \mathrm{R} 2=0.644, \mathrm{Q} 2=-0.070$, and $\mathrm{p}$ value of permutation test $=0.406$ for 2000 repetitions), B) Negative ionization mode untargeted lipidomics (the results of cross validation for 3 components: accuracy $=0.500, R 2$ $=0.477, \mathrm{Q} 2=-0.194, \mathrm{p}$ value of permutation test $=0.148$ for 2000 repetitions), C) Positive ionization mode minor lipids (the results of cross validation for 2 components: accuracy $=0.62$, $R 2=0.694, Q 2=-0.109, p$ value of permutation test $=0.300$ for 2000 repetitions), $D$ ) Negative ionization mode minor lipids mode (the results of cross validation for 3 components, accuracy $=0.471, \mathrm{R} 2=0.635, \mathrm{Q} 2=-0.377, \mathrm{p}$ value of permutation test $=0.462$ for 2000 repetitions); CAD-, T2DM- (red points): without coronary artery disease and without type 2 diabetes 
mellitus, CAD+, T2DM- (green point): with coronary artery disease and without type 2 diabetes mellitus, $C A D+, T 2 D M+$ (blue point): with both coronary artery disease and type 2 diabetes mellitus.
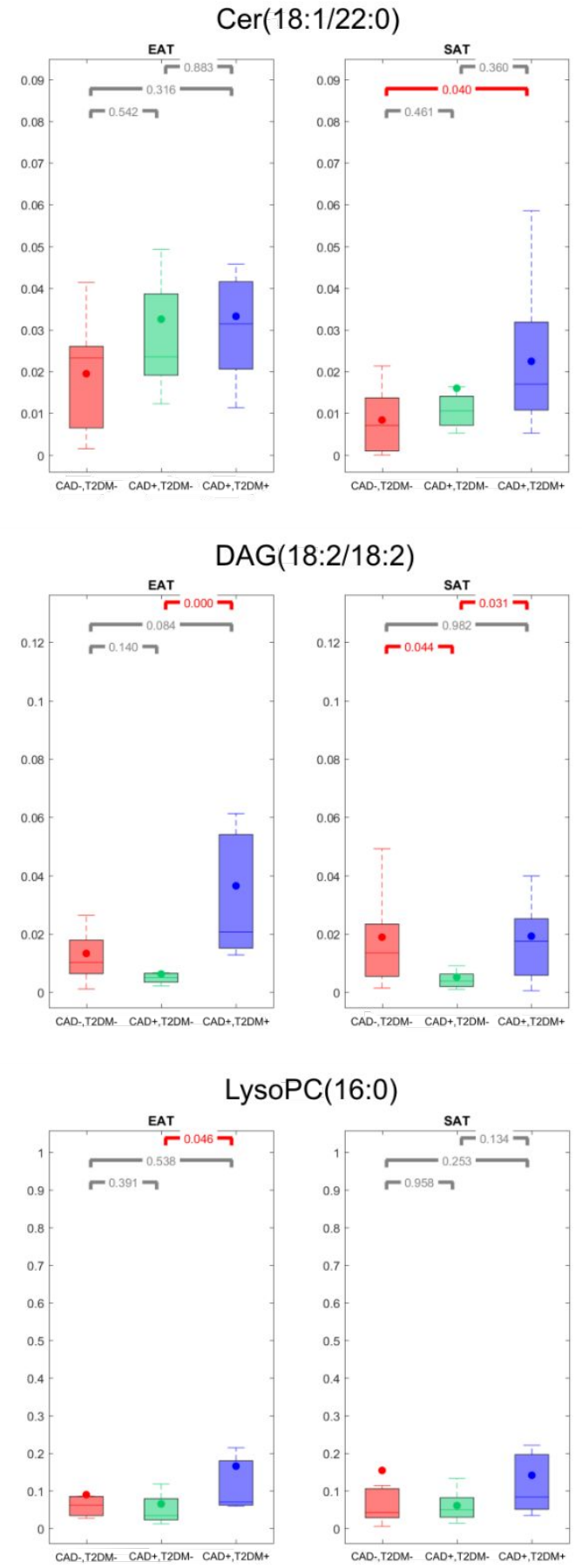

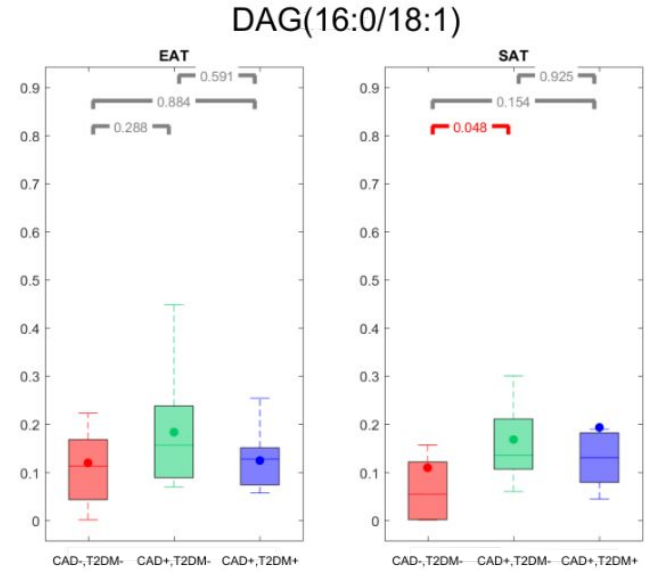

Dihydroxycholesterol
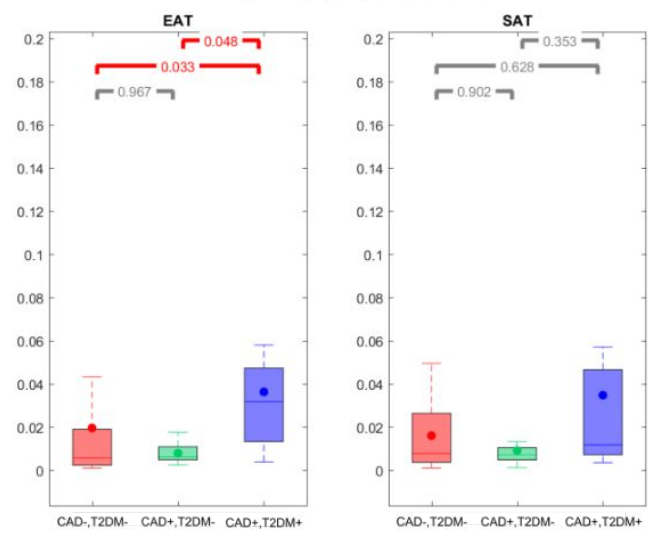

LysoPC(18:1)
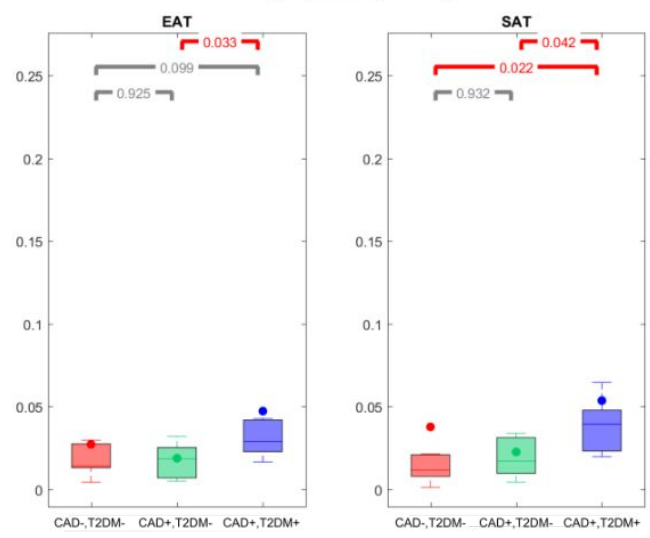

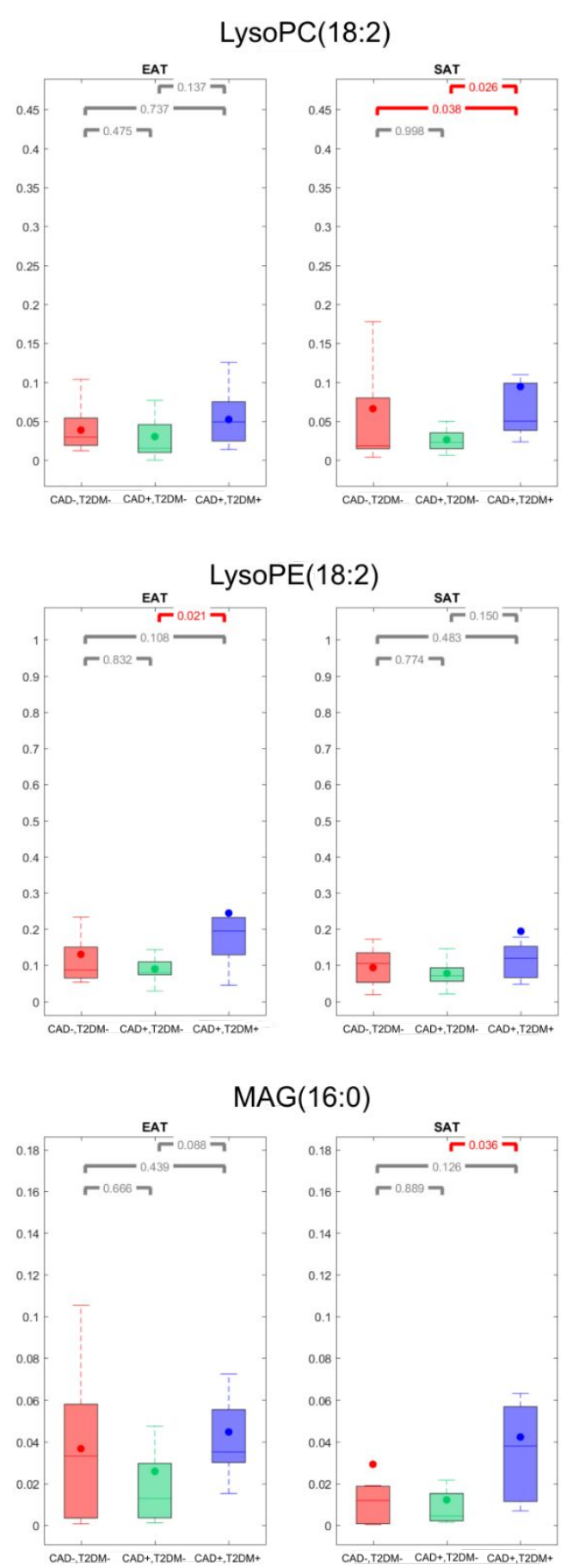
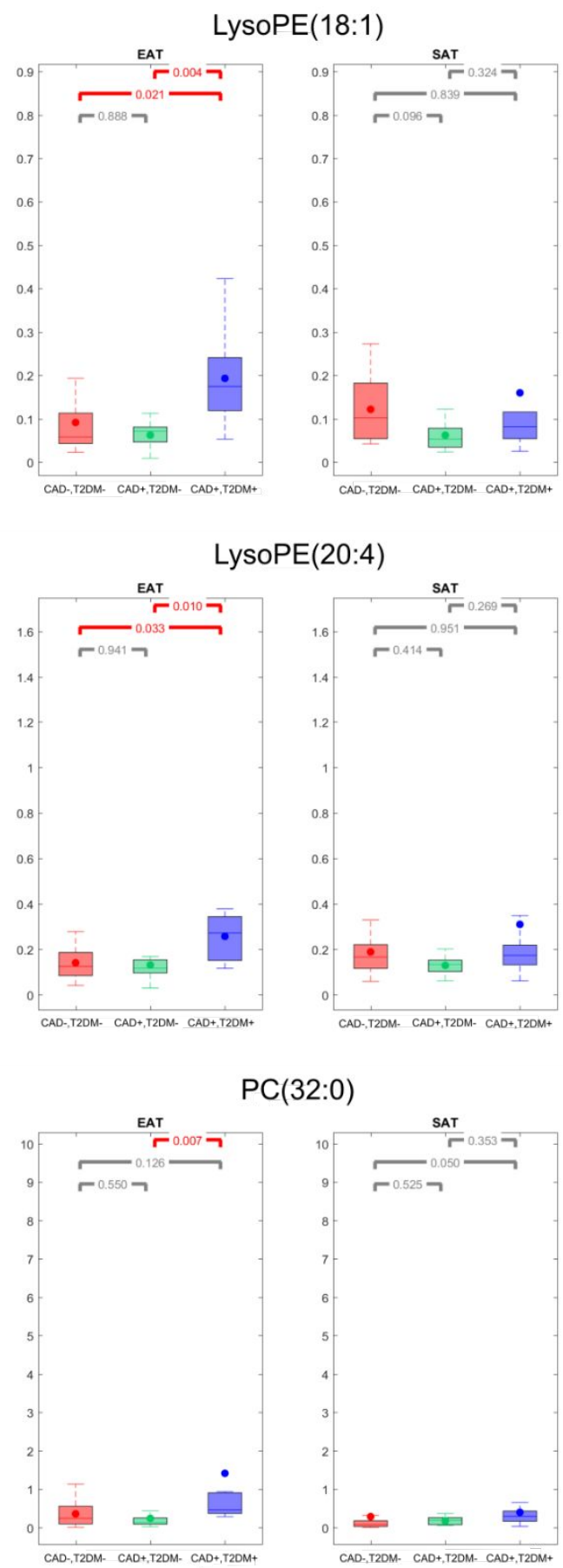

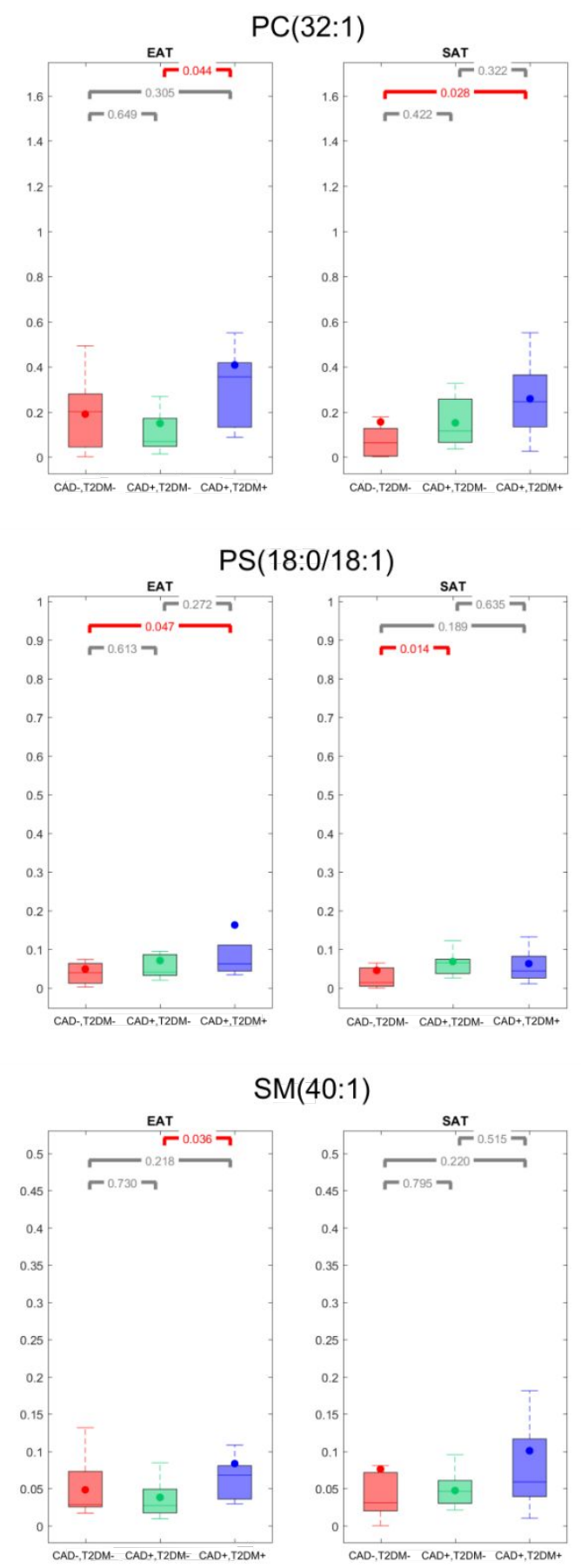

$\mathrm{SM}(40: 1)$

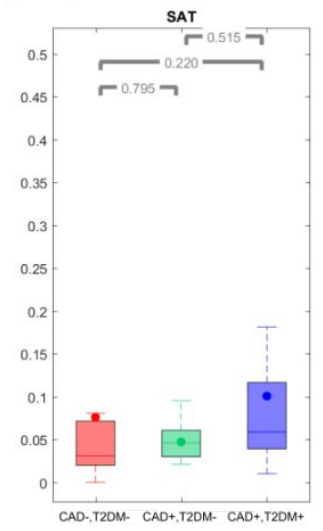

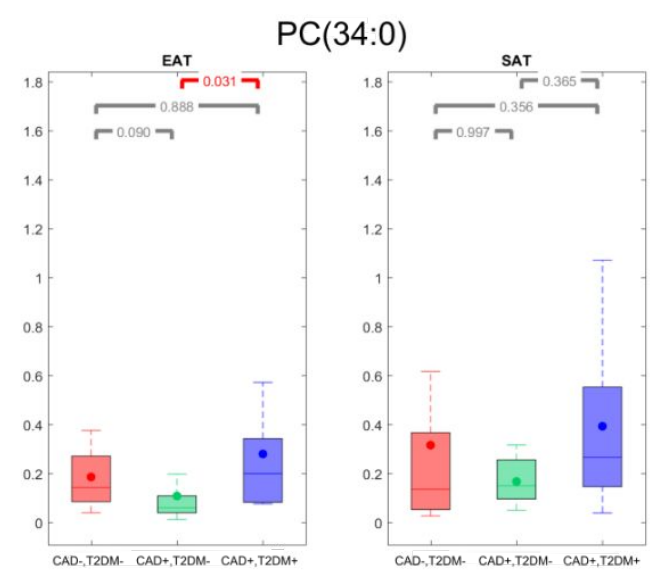
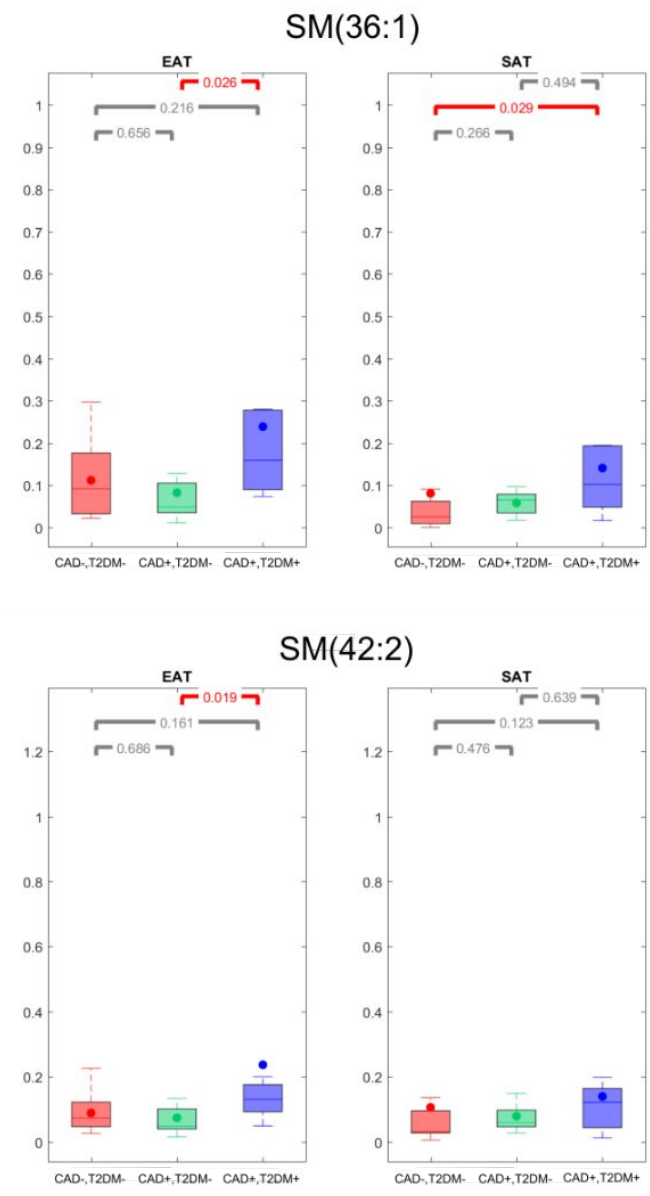

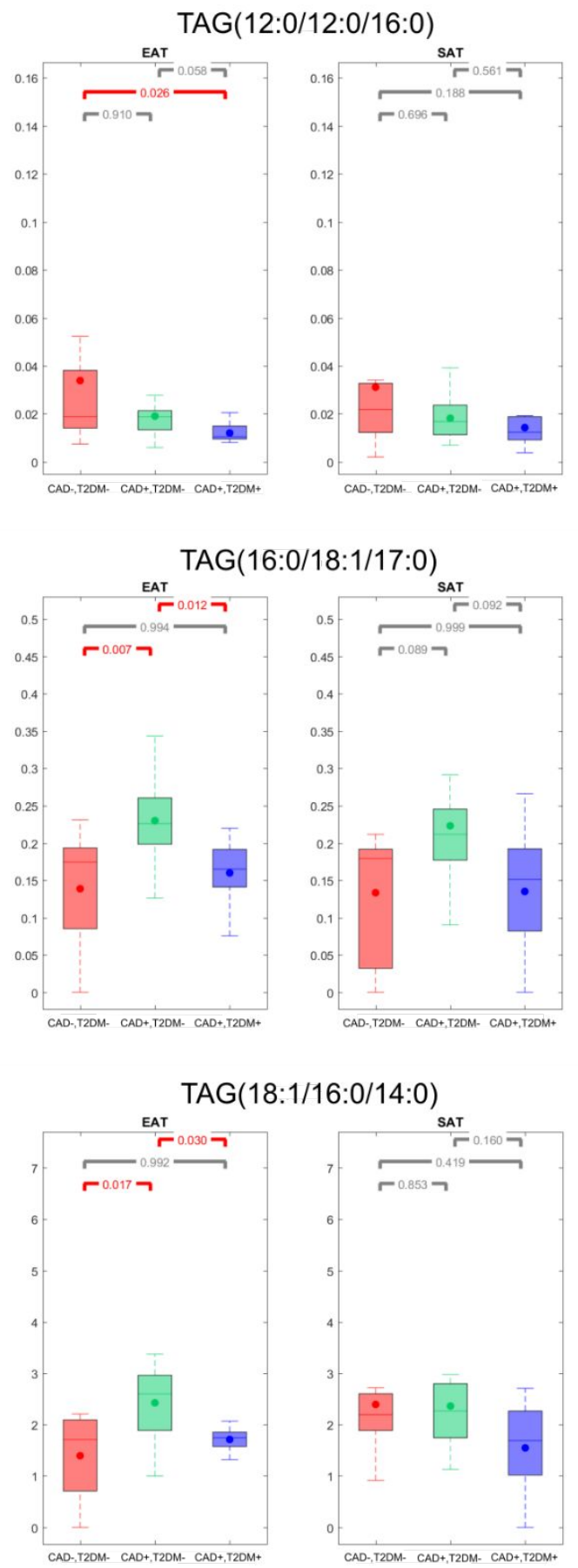

TAG(16:0/14:0/14:0)
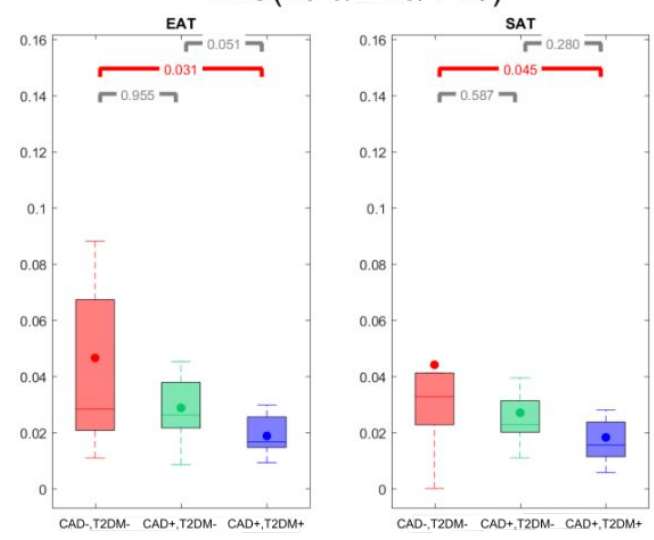

TAG(17:0/18:0/16:0)
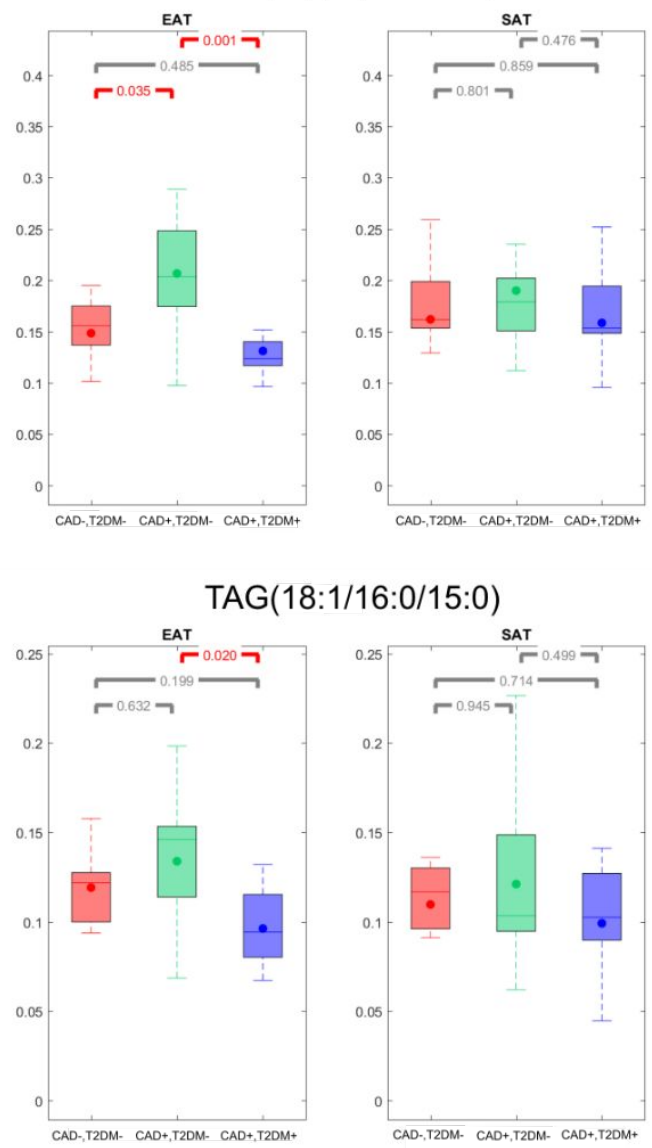

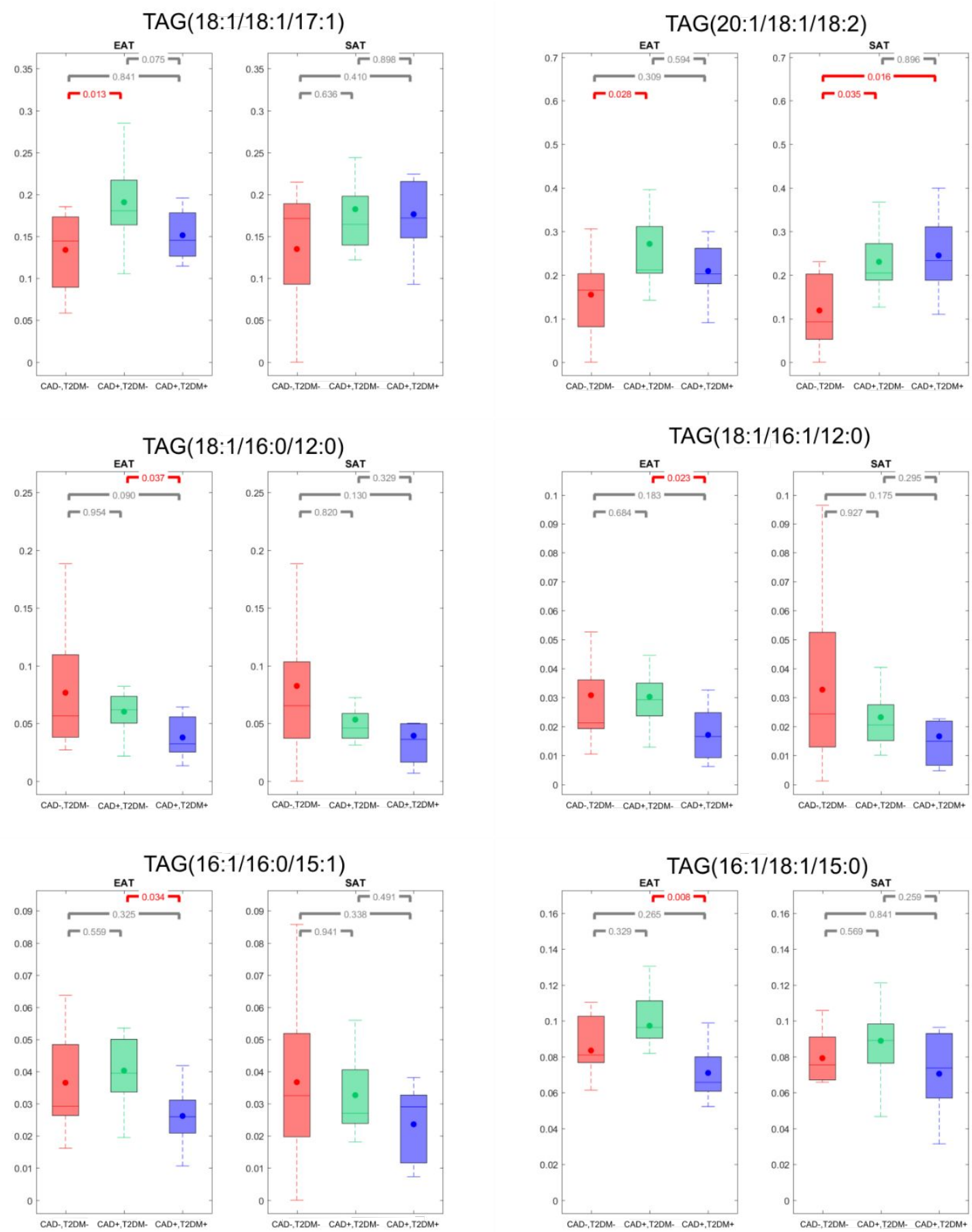

Fig. S32: Boxplots of significantly changed lipids 
SM(36:1) ver. Total Cholesterol

$(R=0.414, p$-value $=0.017)$

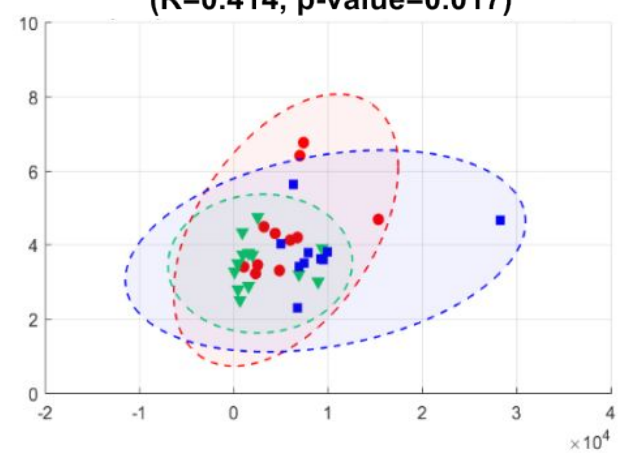

-CAD-,T2DM- vCAD+,T2DM- $=\mathrm{CAD}+, T 2 D M+$

\section{LysoPC(16:0) ver. Total Cholesterol}

$(R=0.416, p$-value $=0.016)$

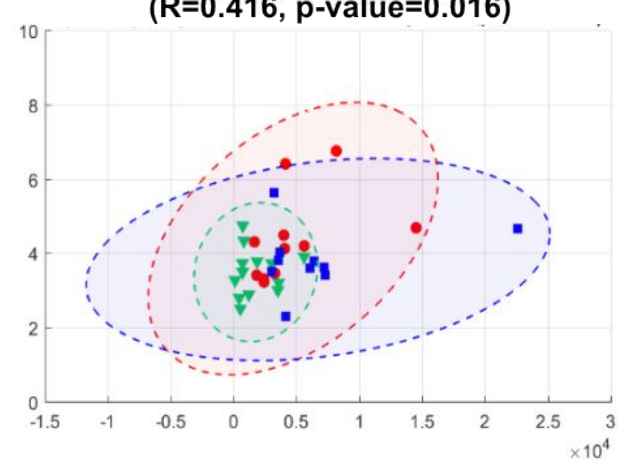

-CAD-,T2DM- $\nabla C A D+, T 2 D M-\quad=C A D+, T 2 D M+$

\section{DAG(18:2/18:2) ver. Total Cholesterol} $(R=0.413, p$-value $=0.017)$

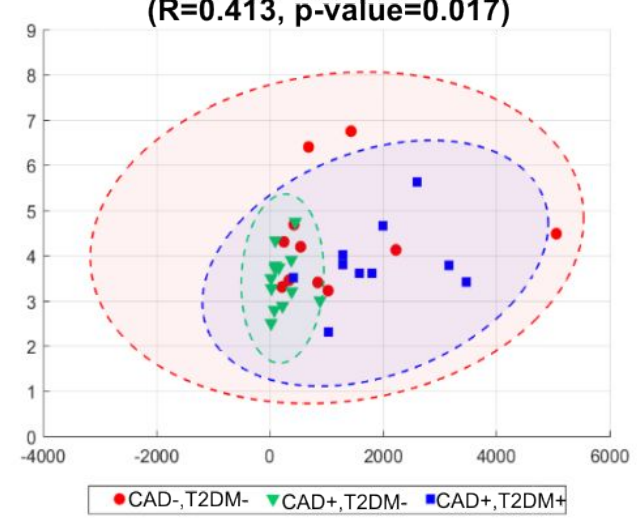

PC(34:0) ver. Total Cholesterol

$(R=0.381, p$-value $=0.029)$

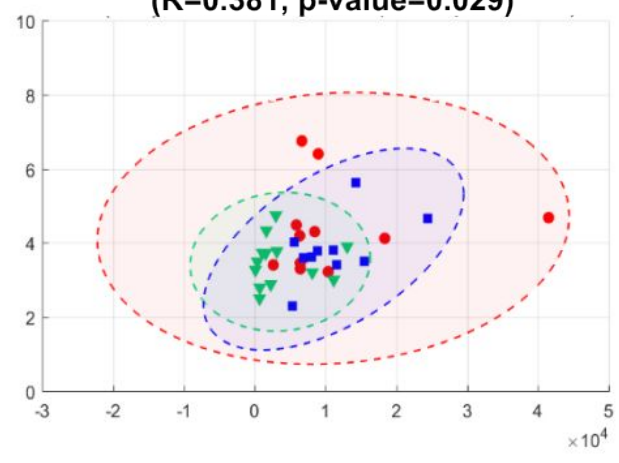

-CAD-,T2DM- $v \mathrm{CAD}+, \mathrm{T} 2 \mathrm{DM}-=\mathrm{CAD}+, \mathrm{T} 2 \mathrm{DM}+$

DAG(18:2/18:2) ver. HDL

$(R=0.399, p-v a l u e=0.021)$

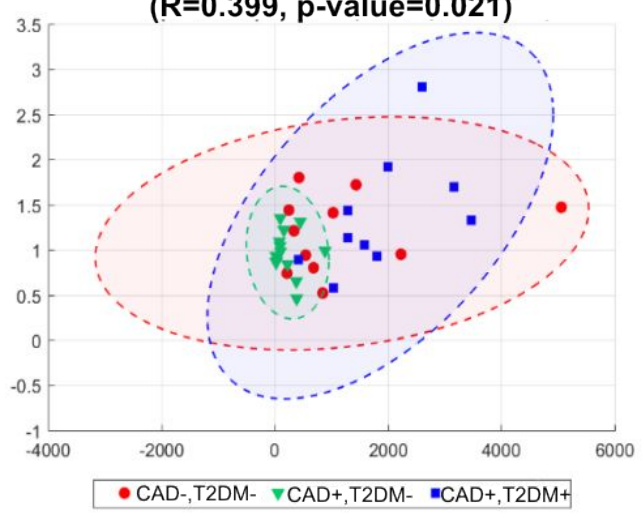

Cer(18:1/22:0) ver. Waist/Hip ratio $(R=0.407$, $p$-value $=0.019)$

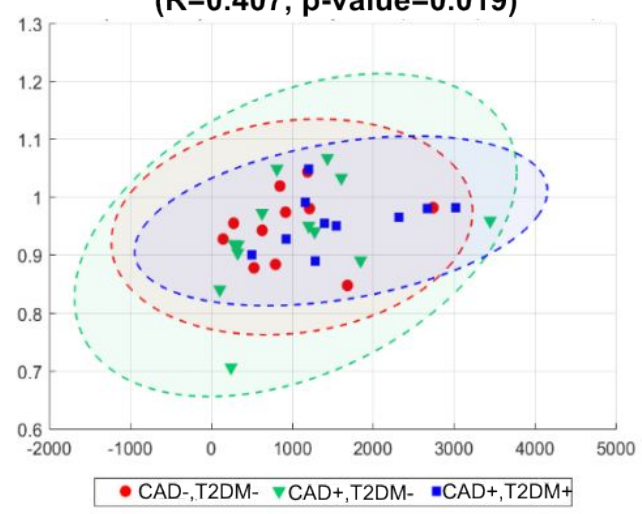




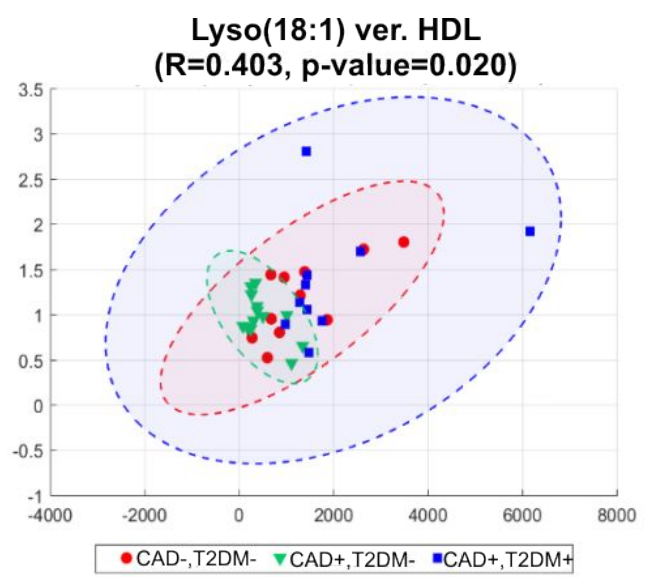

TAG(18:1/16:0/14:0) ver. Waist/Hip ratio $(R=0.395, p$-value $=0.028)$

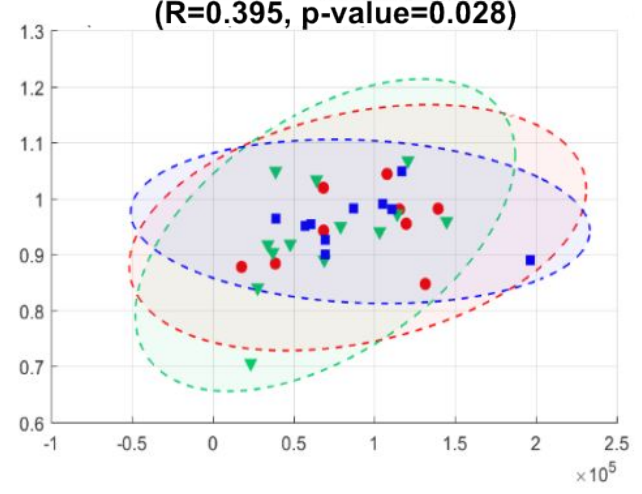

•CAD-,T2DM- vCAD+,T2DM- -CAD+,T2DM+

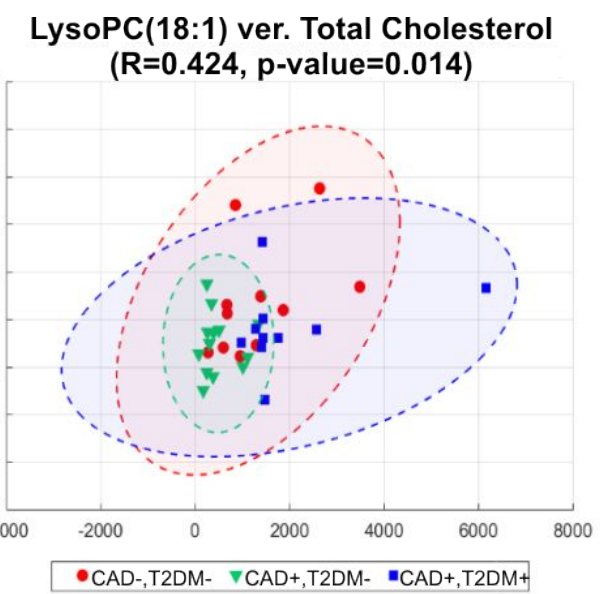

DAG(16:0/18:1) ver. Total Cholesterol $(R=0.371, p-$ value $=0.033)$

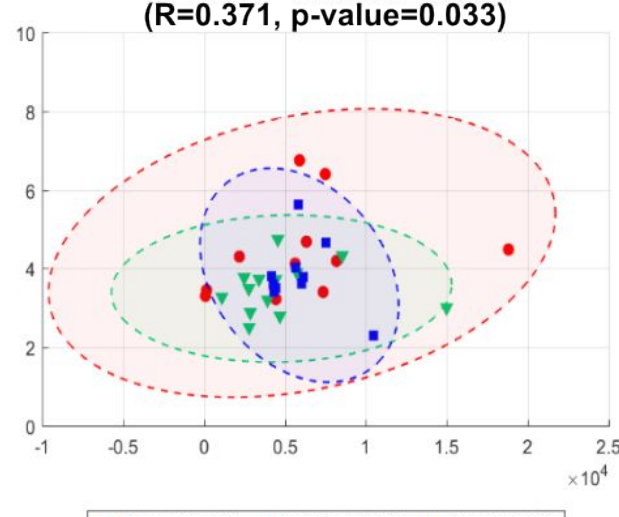

$\bullet$ CAD-,T2DM- VCAD+,T2DM- $\quad$ CCAD+,T2DM+

SM(40:1) ver. Total Cholesterol

$(R=0.432$, $p$-value $=0.012)$

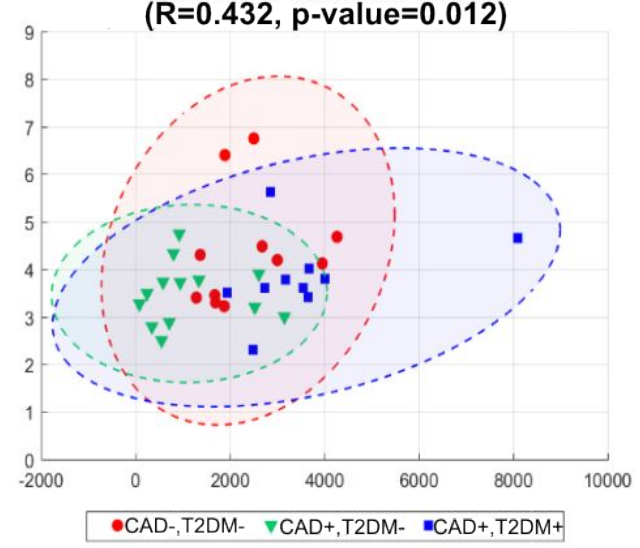




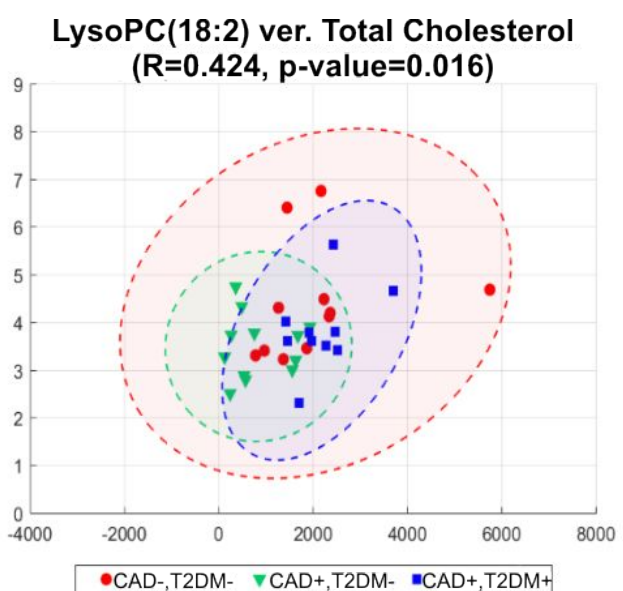

Dihydroxycholesterol ver. Total Cholesterol

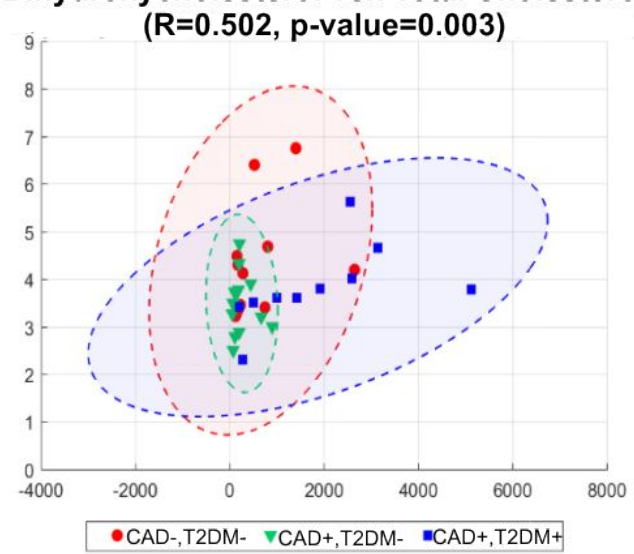

$\mathrm{PC}(32: 1)$ ver. Total Cholesterol

$(R=0.454, p-v a l u e=0.008)$

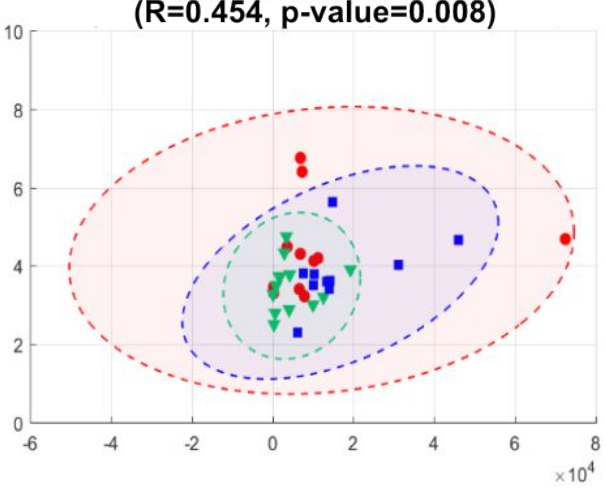

•CAD-,T2DM- VCAD+,T2DM- $=\mathrm{CAD}+, \mathrm{T} 2 \mathrm{DM}+$
TAG(16:0/18:1/17:0) ver. Waist/Hip ratio

$(R=0.389$, $p$-value $=0.030)$

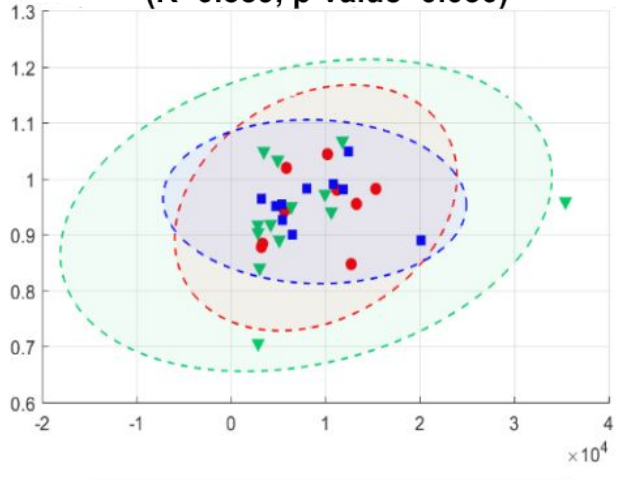

-CAD-,T2DM- VCAD+,T2DM- - CAD+,T2DM+

PC(32:0) ver. Total Cholesterol

$(R=0.405, p$-value $=0.019)$

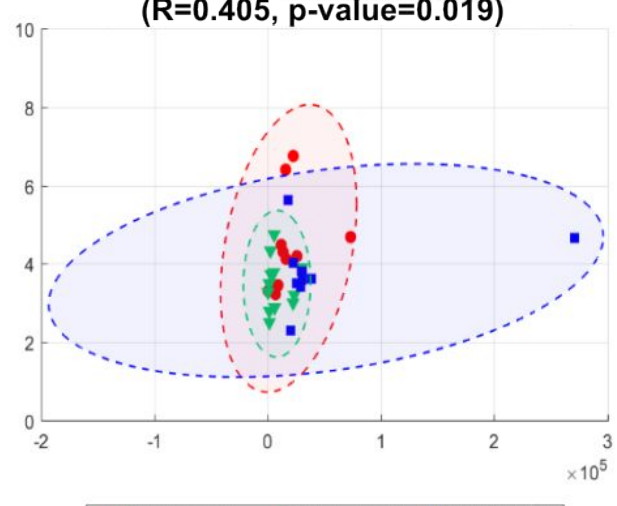

-CAD-,T2DM- $\quad \mathrm{VCAD}+, \mathrm{T} 2 \mathrm{DM}-\quad \mathrm{CAD}+, \mathrm{T} 2 \mathrm{DM}+$
LysoPE(20:4) ver. HDL

$(R=0.388$, $p$-value $=0.026)$

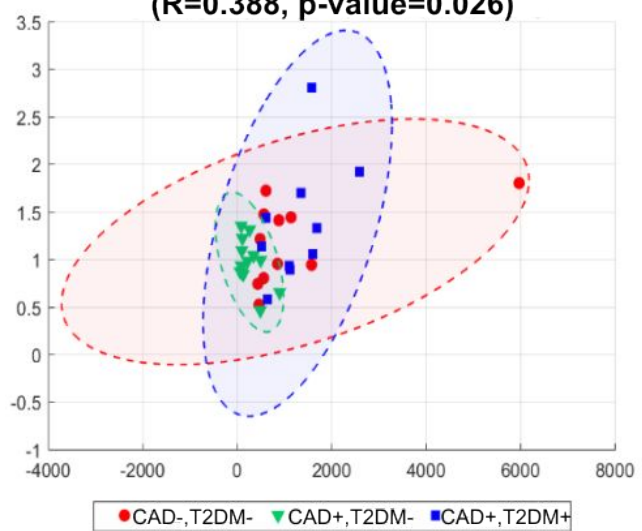



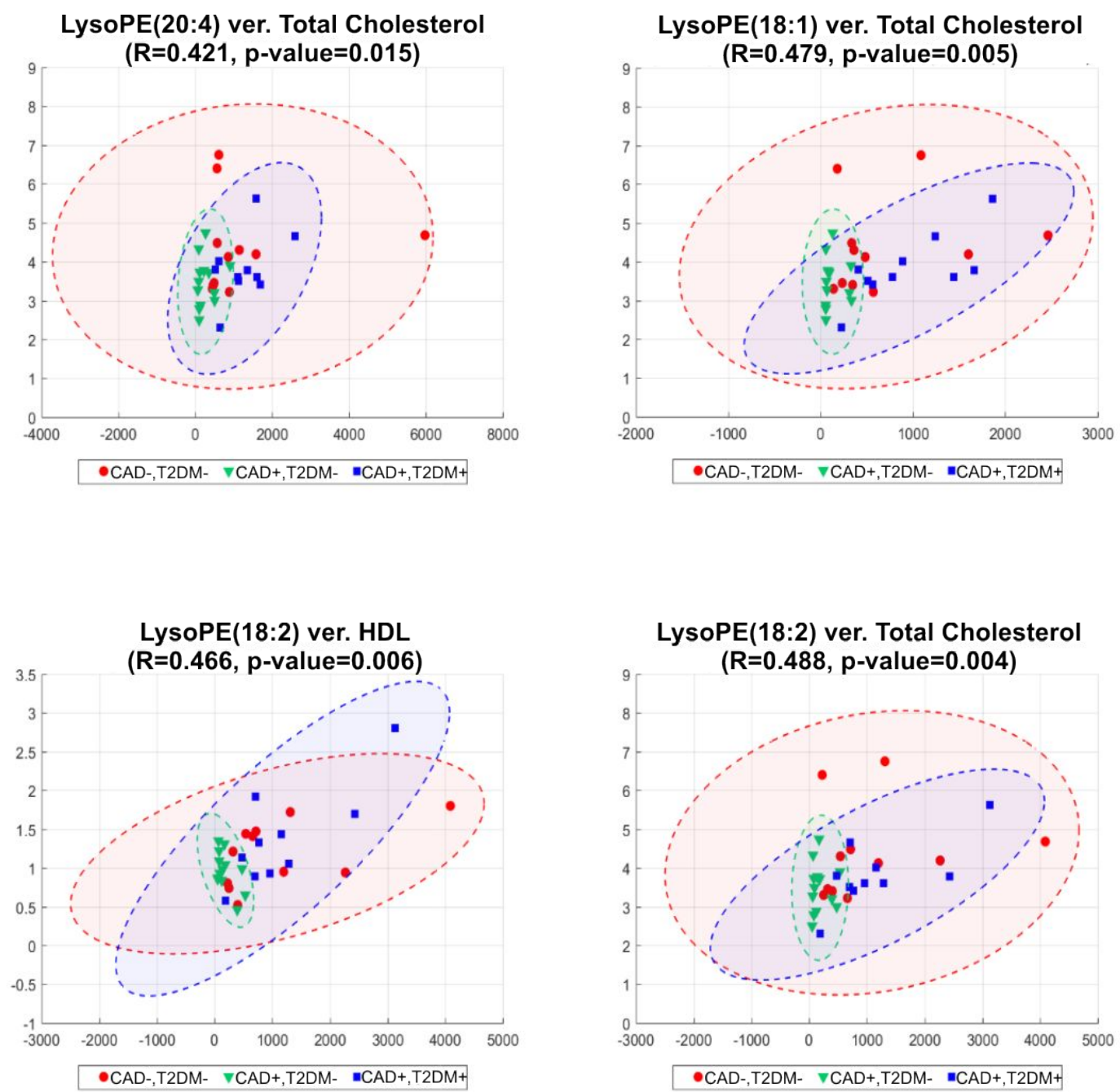

Fig. S33: Spearman's rank correlation of significantly changed lipid in EAT and biochemical parameters
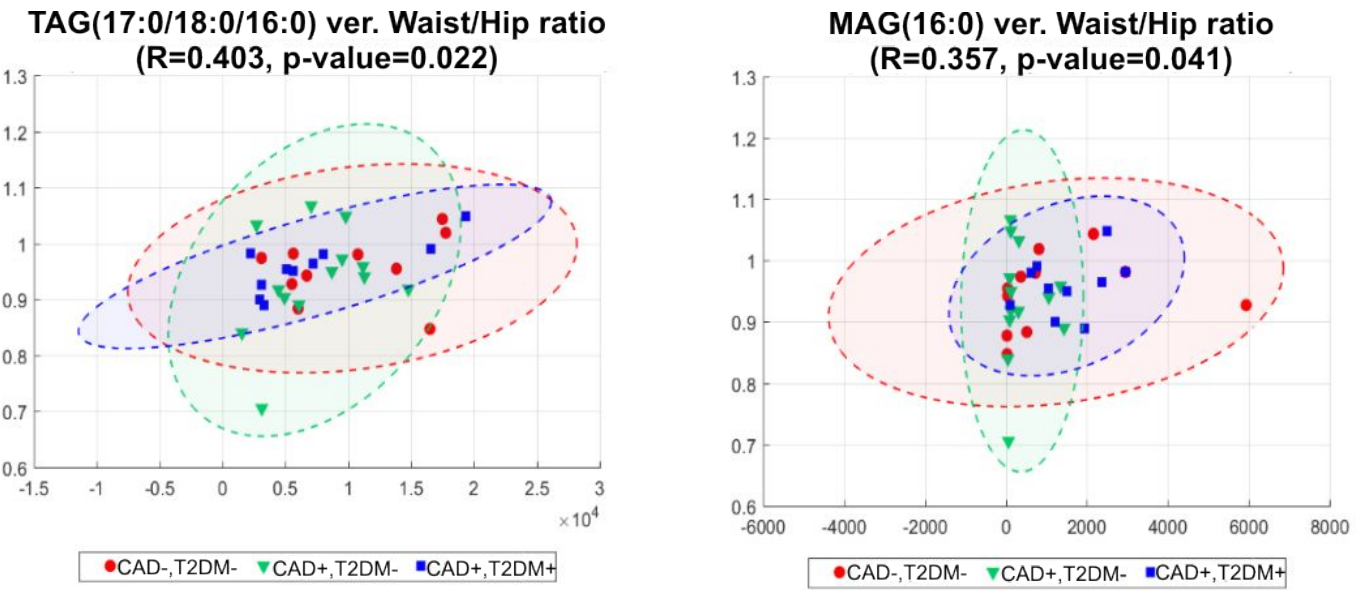

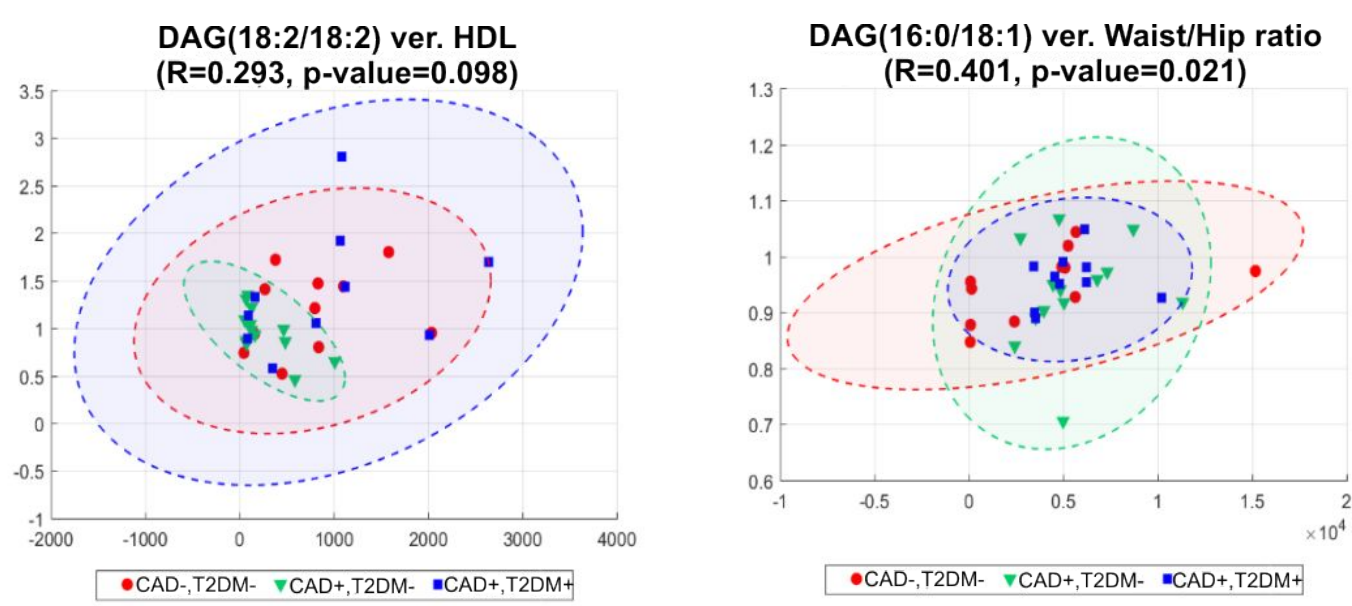

Fig. S34: Spearman's rank correlation of significantly changed lipid in SAT and biochemical parameters 